Federal Reserve Bank of Minneapolis

Research Department Staff Report 342

August 2004

\title{
Inflation, Output and Welfare
}

\author{
Ricardo Lagos* \\ Federal Reserve Bank of Minneapolis \\ and New York University \\ Guillaume Rocheteau* \\ Federal Reserve Bank of Cleveland \\ and Australian National University
}

\begin{abstract}
This paper studies the effects of anticipated inflation on aggregate output and welfare within a search-theoretic framework. We allow money-holders to choose the intensities with which they search for trading partners, so inflation affects the frequency of trade as well as the quantity of output produced in each trade. We consider the standard pricing mechanism for search models, i.e., ex post bargaining, as well as a notion of competitive pricing. If prices are bargained over, the equilibrium is generically inefficient and an increase in inflation reduces buyers' search intensities, output and welfare. If prices are posted and buyers can direct their search, search intensities are increasing with inflation for low inflation rates and decreasing for high inflation rates. The Friedman Rule achieves the first-best allocation and inflation always reduces welfare even though it can have a positive effect on output for low inflation rates.
\end{abstract}

*We are grateful to Randall Wright for his input. We also thank Paul Chen, Patrick Kehoe, Ellen McGrattan, Flavio Menezes, Paulo Monteiro, Graeme Wells and seminar participants at the Australian National University, Indiana University and University of Sydney. Lagos thanks the C.V. Starr Center for Applied Economics at NYU for financial support. The views expressed herein are those of the authors and not necessarily those of the Federal Reserve Bank of Cleveland, the Federal Reserve Bank of Minneapolis, or the Federal Reserve System. 
"In a monetary economy, it is in everyone's private interest to try to get someone else to hold non-interest-bearing cash and reserves. But someone has to hold it all, so all of these efforts must simply cancel out. All of us spend several hours per year in this effort, and we employ thousands of talented and highly-trained people to help us. These person-hours are simply thrown away, wasted on a task that should not have to be performed at all."

Robert E. Lucas Jr., 2000, Inflation and Welfare.

\section{Introduction}

It is a commonly held view that inflation induces economic agents to undertake costly actions in order to reduce their exposure to the inflation tax. The costs associated with these actions are a social waste, part of the welfare cost of inflation. This conventional wisdom is succinctly articulated by Lucas (2000). In this paper we formalize this argument and study its implications for the effects that anticipated inflation has on aggregate output and welfare.

The search-theoretic framework pioneered by Kiyotaki and Wright $(1989,1991,1993)$ explicitly models the frictions that make money essential and relates them to the decentralized nature of trade. This makes the search-based approach a natural setup for our analysis. We let agents choose costly search intensities to determine the frequency with which they trade and study how changes in the rate of inflation affect their search effort decisions, as well as the number of trades, the quantity of output produced in any trade, and welfare in the equilibrium. We view these search efforts as a natural way of formalizing the "efforts" to avoid the inflation tax alluded to in the quote from Lucas (2000).

The particular economic environment we consider has the structure introduced by Lagos and Wright $(2002$, 2003). Agents periodically participate in centralized and decentralized markets. Trade in the centralized market involves all agents and occurs at market clearing prices. The centralized market allows agents to rebalance their cash holdings and at the same time keeps the model tractable. In the decentralized market agents are matched pairwise and trade is bilateral. Lagos and Wright $(2002,2003)$ follow the previous literature and assume that agents in these bilateral situations bargain over the terms of trade. Instead, here we follow Rocheteau and Wright (2002) and generalize the model to allow for different pricing mechanisms.

We first consider bargaining since it is often regarded as the standard pricing mechanism 
for search environments with bilateral meetings. ${ }^{1}$ In this case, buyers respond to increases in inflation by reducing their real money holdings and search intensities. This complementarity between real balances and search intensity can be explained as follows. If agents hold smaller real balances, they enjoy smaller gains from trade when matched. Since each trade yields less utility, agents exert less effort to generate trades. As a result fewer matches occur (extensive margin effect) and less output is produced in every match (intensive margin effect), so aggregate output falls with inflation. Under the Friedman Rule, buyers' search effort choices are generically inefficient because of a congestion externality characteristic of search environments. For example, if buyers have all the bargaining power, their search effort is too high, and as inflation goes up they reduce their search intensities which tends to mitigate this inefficiency. Nevertheless, the negative effect of inflation on real money balances dominates and higher inflation always leads to lower welfare. Note that the prototypical search model with bargaining predicts that individual search effort decreases with inflation and hence fails to rationalize the conventional wisdom discussed above.

We then study the model under price posting with partially directed search-one of the pricing mechanisms considered by Rocheteau and Wright (2002) - as this is a natural notion of competitive pricing for search models. This version of the model has some agents posting prices and other agents directing their search toward a particular price. ${ }^{2}$ For this case the Friedman Rule is the optimal monetary policy and it generates the first-best allocation: buyers choose the socially efficient search intensity and real balances. For high inflation rates, search intensity decreases with inflation, just as in the model with bargaining. But for low inflation rates, an increase in inflation raises buyers' search intensities. Therefore, with the competitive notion of price posting, the model is able to generate predictions that are in line with the conventional wisdom discussed above: agents increase their search intensities when the inflation

\footnotetext{
${ }^{1}$ A model similar to our setup with bargaining but based on Shi (1997) instead of on Lagos and Wright (2002) has been developed independently by Peterson and Shi (2003). They investigate the effect of inflation on price dispersion by combining both a stochastic match-specific component and buyers' endogenous search intensities. A key distinction between our model and theirs is that we allow individual agents to choose their money holdings. Our results differ both in terms of the basic properties of the equilibrium (e.g., existence, uniqueness) as well as in terms of its comparative static properties.

${ }^{2}$ This is the competitive price posting or directed search construct introduced in the labor literature by Moen (1997) and Shimer (1996).
} 
rate is higher, and the additional search costs are socially wasteful. To see the intuition for this result, suppose that prices are set by a group of agents we call sellers, and that another group of agents - buyers - direct their search toward the sellers. Since sellers compete against each other to attract buyers, they internalize the effect of inflation on the buyers' willingness to carry real balances. In equilibrium, competition forces them to partially compensate buyers for the inflation tax by raising the buyer's share in the total surplus of a match. For low inflation rates, the gains from trade that accrue to the buyers increase, so they search harder to generate trades. Furthermore, when this happens, the effect of a change in inflation on aggregate output is ambiguous. For some parametrizations the level of output increases with the rate of inflation. Interestingly, we find that the effect of inflation on output can be nonmonotonic, just as suggested by the recent empirical evidence surveyed by Bullard (1999). ${ }^{3}$ Inflating in excess of the Friedman Rule may help raise output, but it always reduces welfare.

The rest of the paper is organized as follows. Section 2 lays out the environment. Section 3 analyzes the model under ex post bargaining with undirected search. The model with ex ante price-posting and directed search is studied in Section 4. Section 5 concludes. The Appendix contains all the proofs.

\section{The model}

Time is discrete and the horizon infinite. Each period is divided into two subperiods. There are two types of nonstorable consumption goods: search goods (produced and consumed in the first subperiod) and general goods (produced and consumed in the second subperiod). The economy is populated by a set $A_{b} \subseteq[0,1]$ with mass $\mu_{b}$ of agents we call buyers and a set $A_{s} \subseteq[0,1]$ with mass $\mu_{s}$ of sellers. We normalize the population sizes to one: $\mu_{b}=\mu_{s}=1$. All agents are infinitely-lived. Buyers and sellers differ in their preferences and production possibilities. During the second subperiod both have the ability to produce and wish to consume. But in the first subperiod, buyers want to consume but cannot produce while sellers are able to produce but do not wish to consume. This double coincidence of wants problem in the first subperiod

\footnotetext{
${ }^{3}$ Several authors have argued that empirically, inflation seems to have a positive long-run effect on output for low inflation economies. Examples include Bullard and Keating (1995), King and Watson (1997), Ahmed and Rogers (2000) and Rapach (2003).
} 
is what generates an essential role for money. We describe the preferences of buyers and sellers in detail below.

There is an intrinsically useless, perfectly divisible and storable asset called money. We use $M_{t}$ to denote the quantity of money in the first subperiod of period $t$. Let the distributions of money across buyers and sellers at the beginning of the first subperiod be $F^{b}$ and $F^{s}$ respectively. The gross growth rate of the money supply is constant over time and equal to $\gamma$; that is, $M_{t+1}=\gamma M_{t}$. New money is injected, or withdrawn if $\gamma<1$, by lump-sum transfers, or taxes. These transfers take place during the second subperiod and for simplicity we specify that they go only to buyers.

The market structure differs across subperiods. In the first subperiod, trade takes place in a decentralized or search market where agents are matched and trade bilaterally. ${ }^{4}$ In the second subperiod there is a centralized or Walrasian market where agents can trade general goods and money. All agents in this market are price-takers, and the relative price of money in terms of the general good, $\phi_{t}$, adjusts to clear the market.

Search frictions are modeled by an aggregate matching function $\zeta\left(\bar{e} \mu_{b}, \mu_{s}\right)$, where

$$
\bar{e}=\frac{\int_{A_{b}} e_{i} d i}{\mu_{b}}
$$

is the average search intensity of buyers, and $e_{i}$ denotes the search intensity of buyer $i$. (Below, when no confusion may arise, we will often use $e$ to denote $e_{i}$.) Assume $\zeta$ is homogeneous of degree one, twice continuously differentiable, strictly increasing and strictly concave with respect to each argument. Also, suppose $\zeta\left(0, \mu_{s}\right)=\zeta\left(\bar{e} \mu_{b}, 0\right)=0$, and $\zeta\left(\bar{e} \mu_{b}, \mu_{s}\right) \leq \min \left(\mu_{b}, \mu_{s}\right)$ for any $\bar{e} \geq 0$. Letting $\theta \equiv \frac{\mu_{s}}{\bar{e} \mu_{b}}$, an individual buyer's meeting probability is $\alpha_{b}=\frac{e \zeta\left(\bar{e} \mu_{b}, \mu_{s}\right)}{\bar{e} \mu_{b}}=$ $e \zeta(1, \theta)$. To make the notation more compact, we will let $\alpha \equiv \zeta(1, \theta)$ and write an individual buyer's meeting probability as $\alpha_{b}=e \alpha$. We assume that $\alpha \in[0,1]$ for any $\theta \geq 0$, and that $\lim _{\theta \rightarrow \infty} \alpha=1$. Similarly, the meeting probability of a seller is $\alpha_{s}=\alpha / \theta$, and we assume that

\footnotetext{
${ }^{4}$ We will explore two alternative specifications of the search market. In Section 3 we assume buyers and sellers are randomly matched (i.e., search is undirected). In Section 4 we consider a search market in which search can be at least partially directed: Each seller can locate herself in a distinct "submarket" by credibly posting terms of trade and each buyer can direct his search toward a particular submarket but contacts potential trading partners at random within the submarket. This is the competitive (or directed) search construct of Moen (1997) or Shimer (1996).
} 
$\lim _{\theta \rightarrow 0} \alpha_{s}=1 .^{5}$ The dependence of $\alpha_{b}$ and $\alpha_{s}$ on $\theta$ reflects standard search externalities.

The instantaneous utility function of a buyer is

$$
U^{b}(x, y, q, e, \varepsilon)=\varepsilon u(q)-\psi(e)+x-y
$$

where $q$ is consumption in the first subperiod, $x$ is the quantity consumed and $y$ the quantity produced in the second subperiod. Given the linear preferences over $x$ and $y$ it is not worth producing general goods for oneself. ${ }^{6}$ In one of the formulations buyers receive a matchidiosyncratic utility shock $\varepsilon$ in the first subperiod. Shocks $\varepsilon_{t}$ are iid with cumulative distribution $G(\varepsilon)$ on $[0,1]$. The realization of the preference shock is observed by both the buyer and the seller. We assume $u(0)=0, u^{\prime}(0)=\infty, u^{\prime}(q)>0$ and $u^{\prime \prime}(q)<0$ for $q>0$. Finally, the utility cost for a buyer to search with intensity $e$ is $\psi(e)$. We assume that $\psi$ satisfies: $\psi(e) \in[0,+\infty)$ for all $e \in[0,1], \psi(e)=+\infty$ for $e>1, \psi^{\prime}>0, \psi^{\prime \prime}>0, \psi(0)=\psi^{\prime}(0)=0$ and $\lim _{e \rightarrow 1} \psi^{\prime}(e)=+\infty .^{7}$ A buyer's lifetime expected utility is $\mathbb{E}_{0} \sum_{t=0}^{\infty} \beta^{t} U^{b}\left(x_{t}, y_{t}, q_{t}, e_{t}, \varepsilon_{t}\right)$ where $\mathbb{E}_{0}$ is the expectation operator conditional on all information available at $t=0$. The discount factor $\beta \in(0,1)$ is the same for all agents and assumed to be smaller than $\gamma$ throughout the analysis. The instantaneous utility function of a seller is

$$
U^{s}(x, y, q)=-c(q)+x-y
$$

We let $c(0)=c^{\prime}(0)=0, c^{\prime}(q)>0$ and $c^{\prime \prime}(q) \geq 0$ for $q>0$, and $c(q)=u(q)$ for some $q>0$. Lifetime utility for a seller is given by $\mathbb{E}_{0} \sum_{t=0}^{\infty} \beta^{t} U^{s}\left(x_{t}, y_{t}, q_{t}\right)$. We assume that agents are anonymous and that there are no forms of commitment or public memory that would render money inessential.

At this point it may be useful to preview how the economy will work. In the centralized market of a given period $t$ buyers will want to acquire cash to be able to buy their consumption

\footnotetext{
${ }^{5}$ For example, if the matching function is $\zeta\left(\bar{e} \mu_{b}, \mu_{s}\right)=\bar{e} \mu_{b}[1-\exp (-\eta \theta)]$ for some $\eta>0$; then $\alpha=1-$ $\exp (-\eta \theta)$. It is easy to check that $\alpha \in[0,1]$ for all $\theta$, as well as that $\lim _{\theta \rightarrow \infty} \alpha=\lim _{\theta \rightarrow 0} \alpha_{s}=1$.

${ }^{6}$ One can make the model slightly more general by assuming quasi-linear preferences $v(x)-y$. Agents would then consume $x^{*}$ in the second subperiod where $x^{*}$ satisfies $v^{\prime}\left(x^{*}\right)=1$. Normalizing the autarky payoff $v\left(x^{*}\right)-x^{*}$ to 0 , the model would be equivalent to the one we present.

${ }^{7}$ This last condition guarantees that the buyer's optimal choice of intensity will be in $[0,1]$. Together with the assumption $\alpha(\theta) \in[0,1]$ for any $\theta \geq 0$, this guarantees that $\alpha_{b}(e) \in[0,1]$ in any equilibrium. Thus we never have to worry about "corner solutions" for cases in which $\alpha_{b}(e)$ would otherwise exceed 1 . Assume $\rho \geq 1$, then $\psi(e)=\left(\frac{e}{1-e}\right)^{\rho}$ for $e \in[0,1]$ and $\psi(e)=+\infty$ for $e>1$ is a cost function that satisfies all our assumptions.
} 
good in the decentralized market of the following period $t+1$. Since agents are anonymous and they cannot commit, trade must be quid pro quo in the decentralized market. Thus buyers produce during the second subperiod in order to carry some money into the decentralized market. Sellers, on the other hand, never wish to consume in the first subperiod, so they will have no use for cash in the decentralized market. Thus, in the centralized market of period $t$, they will sell off any cash they may have accumulated. Sellers accept money in the decentralized market because they anticipate they will be able to trade it for goods in the second subperiod, in the next meeting of the centralized market. These observations imply that at the beginning of every period, all the cash is being held by buyers. After the round of decentralized trading, some of the money will end up being held by sellers. These sellers will then sell those balances off in the following centralized trading session, and so on.

Throughout the paper we take production in the decentralized market to be the relevant measure of aggregate output:

$$
Y=\zeta\left(\bar{e} \mu_{b}, \mu_{s}\right) \int_{0}^{1} q(\varepsilon) d G(\varepsilon)
$$

where $q(\varepsilon)$ is the quantity traded in a meeting when the buyer receives an $\varepsilon$ preference shock. We define velocity as the nominal value of transactions in the search market divided by the money stock:

$$
\mathcal{V}=\frac{\zeta\left(\bar{e} \mu_{b}, \mu_{s}\right) \int_{0}^{1} d(\varepsilon) d G(\varepsilon)}{M}
$$

where $d(\varepsilon)$ is the amount of money a buyer spends in a decentralized trade when he receives a preference shock $\varepsilon .^{8}$

In the following sections we will be introducing several notions of equilibrium. To assess the efficiency properties of the equilibrium allocations, here we consider the social planner's problem. The planner chooses a nonnegative sequence $\left\{e_{t},\left(x_{t}^{i}, y_{t}^{i}, q_{t}^{i}\right)_{i=b, s}\right\}_{t=0}^{\infty}$ in order to maximize $\mathbb{E}_{0} \sum_{t=0}^{\infty} \beta^{t}\left[U^{b}\left(x_{t}^{b}, y_{t}^{b}, q_{t}^{b}, e_{t}, \varepsilon_{t}\right)+U^{s}\left(x_{t}^{s}, y_{t}^{s}, q_{t}^{s}\right)\right]$, subject to $x_{t}^{b}+x_{t}^{s} \leq y_{t}^{b}+y_{t}^{s}$ and $q_{t}^{b} \leq q_{t}^{s}$. Using (1), (2), the feasibility constraints at equality and writing out the expectations operator explicitly, the planner's objective can be rewritten as:

$$
\sum_{t=0}^{\infty} \beta^{t}\left\{-\psi\left(e_{t}\right)+e_{t} \alpha\left(1 / \bar{e}_{t}\right) \int_{0}^{1}\left\{\varepsilon u\left[q_{t}(\varepsilon)\right]-c\left[q_{t}(\varepsilon)\right]\right\} d G(\varepsilon)\right\} .
$$

\footnotetext{
${ }^{8}$ Velocity in the centralized market equals $\mathcal{V}$ and hence overall velocity is $2 \mathcal{V}$.
} 
Optimality requires $q_{t}(\varepsilon)=q(\varepsilon)$ for all $t$, where $q(\varepsilon)$ satisfies

$$
\frac{\varepsilon u^{\prime}[q(\varepsilon)]}{c^{\prime}[q(\varepsilon)]}=1, \quad \forall \varepsilon \in[0,1] .
$$

For given $\varepsilon$, let $q_{\varepsilon}^{*}$ denote the socially efficient quantity traded that satisfies (5). Note that $q_{0}^{*}=0$ and $\frac{\partial q_{\varepsilon}^{*}}{\partial \varepsilon}=\frac{-u^{\prime}}{\varepsilon u^{\prime \prime}-c^{\prime \prime}}>0$. The socially efficient choice of search intensity for buyer $i$, namely $\bar{e}^{*}$, satisfies

$$
\psi^{\prime}\left(\bar{e}^{*}\right)=\alpha\left(1 / \bar{e}^{*}\right) \eta\left(1 / \bar{e}^{*}\right) \mathcal{S}^{*}
$$

where $\eta(1 / \bar{e}) \equiv 1-\frac{(1 / \bar{e}) \alpha^{\prime}(1 / \bar{e})}{\alpha(1 / \bar{e})}$, and $\mathcal{S}^{*} \equiv \int_{0}^{1}\left[\varepsilon u\left(q_{\varepsilon}^{*}\right)-c\left(q_{\varepsilon}^{*}\right)\right] d G(\varepsilon)$. Note that $\eta(1 / \bar{e}) \in(0,1)$ is the elasticity of the matching function with respect to $\bar{e} \cdot{ }^{9}$ Letting $Q^{*}=\int_{0}^{1} q_{\varepsilon}^{*} d G(\varepsilon)$, aggregate output (in the decentralized market) along the optimal path is

$$
Y^{*}=\zeta\left(\bar{e}^{*} \mu_{b}, \mu_{s}\right) Q^{*}
$$

\section{Bargaining}

This section investigates the output and welfare effects of inflation when prices are determined according to a simple bargaining protocol, i.e., buyers make take-it-or-leave-it offers. This pricing mechanism is the standard benchmark in the search-theoretic literature on monetary exchange since Shi (1995) and Trejos and Wright (1995). At the end of the section we also discuss the implications of giving sellers some bargaining power.

First consider a buyer's problem in the first subperiod. Given his choice of search intensity, $e$, he contacts a seller with probability $\alpha e$. Once matched, the buyer receives $q\left(m_{b}, m_{s}, \varepsilon\right)$ in exchange for $d\left(m_{b}, m_{s}, \varepsilon\right)$ dollars. The notation reflects that in general, the terms of trade $(q, d)$ may depend on the money holdings of the buyer and the seller, $m_{b}$ and $m_{s}$, as well as on the buyer's preference shock, $\varepsilon$. For convenience, we suppress the time subscript $t$ and shorten the subscript $t+1$ to $+1, t-1$ to -1 , and so on. Let $V^{b}(m, \phi)$ be the value function of a buyer with $m$ dollars upon entering the decentralized market when the price of money in terms of general goods in the following centralized market is $\phi$. Similarly let $W^{b}(m, \phi)$ be the value function of a buyer with $m$ dollars upon entering the centralized market in a period where the price of

\footnotetext{
${ }^{9}$ For example, if $\zeta\left(\mu_{b} \bar{e}, \mu_{s}\right)=\bar{e} \mu_{b}[1-\exp (-\eta \theta)]$ with $\eta>0$, then $\eta(\theta)=1-\frac{\eta \theta}{\exp (\eta \theta)-1}$, where $\theta=\frac{\mu_{s}}{\bar{e} \mu_{b}}$.
} 
money in terms of general goods is $\phi .{ }^{10}$ The value functions satisfy

$$
\begin{gathered}
V^{b}(m, \phi)=\max _{e}\left\{-\psi(e)+(1-\alpha e) W^{b}(m, \phi)\right. \\
\left.+\alpha e \int\left\{\varepsilon u\left[q\left(m, m_{s}, \varepsilon\right)\right]+W^{b}\left[m-d\left(m, m_{s}, \varepsilon\right), \phi\right]\right\} d H^{s}\left(m_{s}, \varepsilon\right)\right\},
\end{gathered}
$$

where $d H^{s}\left(m_{s}, \varepsilon\right)=d F^{s}\left(m_{s}\right) d G(\varepsilon) ;$ and

$$
\begin{gathered}
W^{b}(m, \phi)=\max _{\hat{m}, x, y}\left[x-y+\beta V^{b}\left(\hat{m}, \phi_{+1}\right)\right] \\
\text { s.t. } x+\phi \hat{m}=y+\phi(m+T) .
\end{gathered}
$$

$T=M_{+1}-M$ is the monetary transfer the buyer receives and $\hat{m}$ is the money he chooses to take into the decentralized market of the following subperiod. Using the constraint to substitute for $x-y$ we have

$$
W^{b}(m, \phi)=\phi(m+T)+\max _{\hat{m} \geq 0}\left[\beta V^{b}\left(\hat{m}, \phi_{+1}\right)-\phi \hat{m}\right] .
$$

From (9), we see that the maximizing choice of $\hat{m}$ is independent of $m$, and $W^{b}(m+d, \phi)-$ $W^{b}(m, \phi)=\phi d$. This second observation implies

$$
\begin{gathered}
V^{b}(m, \phi)=W^{b}(m, \phi) \\
+\max _{e \geq 0}\left\{-\psi(e)+\alpha e \int\left\{\varepsilon u\left[q\left(m, m_{s}, \varepsilon\right)\right]-\phi d\left(m, m_{s}, \varepsilon\right)\right\} d H^{s}\left(m_{s}, \varepsilon\right)\right\} .
\end{gathered}
$$

Let $V^{s}(m, \phi)$ and $W^{s}(m, \phi)$ be the corresponding value functions for sellers. The value function of a seller entering the first subperiod with $m$ dollars satisfies

$$
\begin{gathered}
V^{s}(m, \phi)=(1-\alpha \bar{e}) W^{s}(m, \phi) \\
+\alpha \bar{e} \int\left\{-c\left[q\left(m_{b}, m, \varepsilon\right)\right]+W^{s}\left[m+d\left(m_{b}, m, \varepsilon\right), \phi\right]\right\} d H^{b}\left(m_{b}, \varepsilon\right)
\end{gathered}
$$

with $d H^{b}\left(m_{b}, \varepsilon\right)=d F^{b}\left(m_{b}\right) d G(\varepsilon)$. The value function of a seller entering the centralized market with $m$ dollars satisfies

$$
\begin{gathered}
W^{s}(m, \phi)=\max _{\hat{m}, x, y}\left\{x-y+\beta V^{s}\left(\hat{m}, \phi_{+1}\right)\right\} \\
\text { s.t. } x+\phi \hat{m}=\phi m+y .
\end{gathered}
$$

\footnotetext{
${ }^{10}$ By expressing the value functions as $V^{i}(m, \phi)$ and $W^{i}(m, \phi)$ we can think of this as a stationary dynamic programming problem even if $\left\{\phi_{t}\right\}$ is not stationary. See Lagos and Wright (2002) for details.
} 
Using the constraint to substitute $x-y$ out of the objective, we have

$$
W^{s}(m, \phi)=\phi m+\max _{\hat{m} \geq 0}\left[\beta V^{s}\left(\hat{m}, \phi_{+1}\right)-\phi \hat{m}\right] .
$$

Again, note that $\hat{m}$ is independent of $m$, and that $W^{s}(m, \phi)=\phi m+W^{s}(0, \phi)$, so

$$
V^{s}(m, \phi)=W^{s}(m, \phi)+\alpha \bar{e} \int\left\{-c\left[q\left(m_{b}, m, \varepsilon\right)\right]+\phi d\left(m_{b}, m, \varepsilon\right)\right\} d H^{b}\left(m_{b}, \varepsilon\right) .
$$

\subsection{Prices}

Prices in the decentralized market are determined by take-it-or-leave-it offers by buyers. Consider a match between a buyer and a seller where the buyer holds $m$ units of money and his preference shock is $\varepsilon$. The terms of trade $(q, d)$ satisfy

$$
\max _{q, d \leq m}[\varepsilon u(q)-\phi d] \quad \text { s.t. } \quad-c(q)+\phi d \geq 0 .
$$

The solution is $q=q_{\varepsilon}^{*}$ and $d=\frac{c\left(q_{\varepsilon}^{*}\right)}{\phi}$ if $c\left(q_{\varepsilon}^{*}\right) \leq \phi m$; or $c(q)=\phi m$ and $d=m$ otherwise. ${ }^{11}$ In either case the pair $(q, d)$ is independent of the seller's money holdings. Moreover, the solution only depends on the buyer's real money balances $z=\phi m$, so we write it as

$$
q_{\varepsilon}(z)= \begin{cases}q_{\varepsilon}^{*} & \text { if } z \geq c\left(q_{\varepsilon}^{*}\right) \\ \hat{q}(z) & \text { otherwise }\end{cases}
$$

where $\hat{q}(z)$ is the $q$ that solves $c(q)=z$. Since $q_{\varepsilon}^{*}$ is an increasing function of $\varepsilon$, there is a threshold $R(z)$ such that $q_{\varepsilon}(z)=q_{\varepsilon}^{*}$ if $\varepsilon \leq R(z)$ and $q_{\varepsilon}(z)=\hat{q}(z)$ for all $\varepsilon>R(z)$. In other words, $R(z)$ is the $\varepsilon$-draw that renders the buyer's cash constraint in the bargaining just binding. The threshold $R$ satisfies $c\left(q_{R}^{*}\right)=z$ or equivalently $R u^{\prime}[\hat{q}(z)]=c^{\prime}[\hat{q}(z)]$. For future reference, note that $R(0)=0, R\left[c\left(q_{1}^{*}\right)\right]=1$ and $R^{\prime}(z)>0$ for $z \in\left[0, c\left(q_{1}^{*}\right)\right)$. Also,

$$
q_{\varepsilon}^{\prime}(z)=\left\{\begin{array}{ll}
\frac{1}{c^{\prime}(q)} & \text { if } \varepsilon>R(z) \\
0 & \text { otherwise }
\end{array} \quad \text { and } q_{\varepsilon}^{\prime \prime}(z)= \begin{cases}\frac{-c^{\prime \prime}(q)}{\left[c^{\prime}(q)\right]^{3}} & \text { if } \varepsilon>R(z) \\
0 & \text { otherwise. }\end{cases}\right.
$$

\footnotetext{
${ }^{11}$ When determining his take-it-or-leave-it offer to a seller holding $m_{s}$ dollars, a buyer with $m$ dollars faces the following problem:$$
\max _{q, d \leq m}\left[\varepsilon u(q)+W^{b}(m-d, \phi)-W^{b}(m, \phi)\right] \text {, s.t. }-c(q)+W^{s}\left(m_{s}+d, \phi\right)=W^{s}\left(m_{s}, \phi\right) .
$$

To obtain (14) we use the fact that $W^{i}(m+d, \phi)-W^{i}(m, \phi)=\phi d$ for $i=b, s$.
} 


\subsection{Equilibrium}

Let $Z_{t} \equiv \phi_{t} M_{t}$ denote aggregate real balances. Hereafter we specialize the analysis to stationary equilibria with constant aggregate real balances, i.e., with $Z_{+1}=Z$ for all $t$, which implies $\phi / \phi_{+1}=\gamma$. Define $\tau \equiv \phi T$, the real transfer received by the buyer, and

$$
\mathcal{S}(z) \equiv \int_{0}^{1}\left\{\varepsilon u\left[q_{\varepsilon}(z)\right]-c\left[q_{\varepsilon}(z)\right]\right\} d G(\varepsilon),
$$

the expected surplus of a match. The following Lemma gives the closed form expressions for the value functions rewritten in terms of real balances.

Lemma 1 (a) Sellers do not carry cash into the decentralized market. Moreover,

$$
V^{s}(z)=z \quad \text { and } \quad W^{s}(z)=z
$$

(b) Let $g(z) \equiv \tau+\max _{e}[\alpha e \mathcal{S}(z)-\psi(e)]$. The value functions for the buyer are

$$
\begin{aligned}
V^{b}(z) & =\frac{B}{1-\beta}+g(z)+z, \text { and } \\
W^{b}(z) & =\tau+z+\max _{z}[\beta g(z)+(\beta-\gamma) z]+\frac{\beta}{1-\beta} B,
\end{aligned}
$$

where $B \equiv \max _{z}[\beta g(z)+(\beta-\gamma) z]$.

Sellers have no use for money in the decentralized market, so provided $\gamma \leq \beta$, they choose $m^{s}=0$ in the centralized market. Consequently, sellers' expected utility at the beginning of a period is $V^{s}(0)=0$. Buyers choose real balances in the centralized market and search intensity upon entering the decentralized market. From (18), their decision problem is:

$$
\max _{e, z}\left[\alpha e \mathcal{S}(z)-\psi(e)+\left(\frac{\beta-\gamma}{\beta}\right) z\right] .
$$

The following lemma establishes some properties of the individual decision problem faced by buyers in a stationary equilibrium.

Lemma 2 (a) The buyer's optimal choice of search intensity as a function of his real balances, $e(z)$, is characterized by

$$
\psi^{\prime}(e)=\alpha \mathcal{S}(z)
$$


Moreover, $e(z) \in[0,1), e^{\prime}(z)>0$ for all $z \in\left[0, c\left(q_{1}^{*}\right)\right)$ and $e^{\prime}(z)=0$ for all $z \geq c\left(q_{1}^{*}\right)$.

(b) The (set of) optimal choice(s) of real balances $D(\bar{e}, \gamma)=\arg \max _{z}[\beta g(z)+(\beta-\gamma) z]$ is nonempty, compact-valued and upper-hemi continuous. In addition, $D(\bar{e}, \gamma) \subseteq\left[0, c\left(q_{1}^{*}\right)\right)$ is decreasing in $(\bar{e}, \gamma)$.

The optimal choice of search effort given by (20) equates the marginal disutility from search to the buyer's expected gains from trade. Part (a) also shows that search intensity and real money balances are complements. Intuitively, search effort is increasing in the buyer's expected surplus from trade, $\mathcal{S}(z)$, and higher real balances mean a higher expected surplus. This complementarity between money demand and search intensity implies that the buyer's maximization problem need not be concave. Part (b) provides a complete characterization of the set of money demands that maximize the buyer's problem. The largest solution will be strictly below $c\left(q_{1}^{*}\right)$, namely the amount of cash that renders the buyer's cash constraint slack for every possible realization of the preference shock. In other words, as long as $\beta<\gamma$, every buyer's cash constraint will bind with positive probability. In terms of comparative statics, as inflation $(\gamma)$ or congestion in the search market $(\bar{e})$ increase, buyers reduce both their investments in money and search effort. Notice that even though the buyer's problem may have multiple solutions, our comparative static results do not rely on an arbitrary selection rule: according to part (c), any selection from $\arg \max [\beta g(z)+(\beta-\gamma) z]$ is decreasing in $(\bar{e}, \gamma) .{ }^{12}$ The first-order condition for real balances, i.e., $\mathcal{S}^{\prime}(z)=\frac{\gamma-\beta}{\alpha e \beta}$, or equivalently,

$$
\int_{\frac{c^{\prime}[q(z)]}{u^{\prime}[q(z)]}}^{1}\left\{\frac{\varepsilon u^{\prime}[q(z)]}{c^{\prime}[q(z)]}-1\right\} d G(\varepsilon)=\frac{\gamma-\beta}{e \alpha \beta}
$$

is used in Lemma 2 only to establish the strict monotonicity of the maximizers in the very last step of the proof of part (c). We are now ready to define an equilibrium.

Definition 1 Given a money supply process $M_{t+1} / M_{t}=\gamma$, a stationary monetary equilibrium is a collection $\left\{\left(z_{i}, e_{i}\right)_{i \in[0,1]}, \bar{e}\right\}$ and a sequence $\left\{\phi_{t}, Z_{t}\right\}$ with $Z_{t}=Z$ for all $t$, such that:

\footnotetext{
${ }^{12}$ The correspondence $D(\bar{e}, \gamma)$ is decreasing in $(\bar{e}, \gamma)$ if $\left(\bar{e}^{\prime \prime}, \gamma^{\prime \prime}\right) \succ\left(\bar{e}^{\prime}, \gamma^{\prime}\right), z^{\prime} \in D\left(\bar{e}^{\prime}, \gamma^{\prime}\right)$, and $z^{\prime \prime} \in D\left(\bar{e}^{\prime \prime}, \gamma^{\prime \prime}\right)$, then $z^{\prime \prime} \leq z^{\prime}$ (and $z^{\prime \prime}<z^{\prime}$ if $z^{\prime \prime}>0$ ). Here " $\succeq$ " denotes the pairwise ordering relation on $\mathbb{R}^{2}$. That is, for any $\left(x^{\prime}, y^{\prime}\right),\left(x^{\prime \prime}, y^{\prime \prime}\right) \in \mathbb{R}^{2}$ we write $\left(x^{\prime \prime}, y^{\prime \prime}\right) \succeq\left(x^{\prime}, y^{\prime}\right)$ when $x^{\prime \prime} \geq x^{\prime}$ and $y^{\prime \prime} \geq y^{\prime}$. We write $\left(\gamma^{\prime \prime}, \bar{e}^{\prime \prime}\right) \succ\left(\gamma^{\prime}, \bar{e}^{\prime}\right)$ if $\left(x^{\prime \prime}, y^{\prime \prime}\right) \succeq\left(x^{\prime}, y^{\prime}\right)$ and $\left(\gamma^{\prime \prime}, \bar{e}^{\prime \prime}\right) \neq\left(\gamma^{\prime}, \bar{e}^{\prime}\right)$.
} 
(B1) Given $\bar{e}, z_{i} \in D(\bar{e}, \gamma)$, and $e_{i}=e\left(z_{i}\right)$ is given (20), for every buyer $i \in[0,1]$

(B2) $\int_{[0,1]} e_{i} d i=\bar{e}$

(B3) $\int_{[0,1]} z_{i} d i=Z$

(B4) $\phi_{t}=\frac{Z}{M_{t}}$

Condition (B1) says that the allocation $\left(z_{i}, e_{i}\right)_{i \in[0,1]}$ must solve the buyer's problem. We do not impose symmetry across buyers: if the set of maximizers is not a singleton, we allow buyers to make different choices. (B2) defines the average search intensity and (B3) is the clearing condition for the money market. (B4) maps real balances and the money supply into the reciprocal of the price level. An equilibrium can be found by first solving the buyer's problem for $z_{i}(\bar{e})$ and $e_{i}=h\left[z_{i}(\bar{e}), \bar{e}\right]$, where $z_{i}(\bar{e}) \in D(\bar{e}, \gamma)$ and $h\left[z_{i}(\bar{e}), \bar{e}\right]$ is implicitly defined by (20); and then using these choices to construct the map $\int_{[0,1]} h\left[z_{i}(\bar{e}), \bar{e}\right] d i$. Finding an equilibrium then amounts to finding a fixed point $\bar{e}=\int_{[0,1]} h\left[z_{i}(\bar{e}), \bar{e}\right] d i$. Once a fixed point $\bar{e}$ has been found, (B3) can be used to get $Z=\int_{[0,1]} z_{i}(\bar{e}) d i$, and given $Z$, we can read $\phi_{t}$ from $(B 4)$. The following proposition establishes the main properties of the equilibrium.

Proposition 1 There exists a stationary monetary equilibrium if

$$
\max _{e, z}\{\beta[e \mathcal{S}(z)-\psi(e)]+(\beta-\gamma) z\}>0
$$

The average equilibrium search intensity $\bar{e}$ is uniquely determined and it is decreasing in $\gamma$.

The condition in Proposition 1 says that a monetary equilibrium exists if the inflation rate $\gamma$ is not too high. In addition, the proposition establishes that the average search intensity $\bar{e}$ is uniquely determined, which reflects the absence of strategic complementarities among agents (See Figure 3). Because real money balances and search intensities are complements, buyers reduce their search intensities when real balances are "taxed" at a higher rate. The proposition does not rule out the possibility of multiplicity of equilibria. However, in case of multiplicity, all buyers and sellers would get the same payoff in any of the equilibria. ${ }^{13}$

\footnotetext{
${ }^{13}$ In general, the buyer's problem (19) need not be strictly concave, allowing for the possibility of multiple solutions. When this is the case, there may be equilibria only differing in the fractions of buyers choosing each solution.
} 
In order to study the effects of inflation on output and welfare, we focus on the case where the solution to the buyer's problem is unique. ${ }^{14}$ Using (3) and (7) output is

$$
Y=\zeta\left(\bar{e} \mu_{b}, \mu_{s}\right)\left\{Q^{*}-\int_{R(z)}^{1}\left[q_{\varepsilon}^{*}-\hat{q}(z)\right] d G(\varepsilon)\right\}
$$

where $\hat{q}(z)=c^{-1}(z)$ and $R(z)=c^{\prime}[\hat{q}(z)] / u^{\prime}[\hat{q}(z)]$. We study the effects of inflation on welfare from the perspective of a buyer upon entering the decentralized market. We ignore sellers since their expected utility is 0 in equilibrium. Along the equilibrium path, we have

$$
(1-\beta) V^{b}(z)=\alpha e(z) \mathcal{S}(z)-\psi[e(z)]
$$

where $z \in \arg \max _{\hat{z}}[\beta g(\hat{z})+(\beta-\gamma) \hat{z}]$ and $e(z)$ is implicitly defined by $(20)$. Note that this welfare criterion is essentially the same one used by the planner.

Proposition 2 Equilibrium is socially inefficient. Furthermore, aggregate output and welfare are decreasing with inflation.

\subsection{Discussion}

A surprising feature of the model with ex post bargaining is that buyers do not increase their search intensity to spend their cash faster as the rate of anticipated inflation increases. In fact, what happens is that real balances fall, and since real balances and search effort are complements (recall part (a) of Lemma 2), buyers reduce their intensity of search. Since they can get less for their cash, buyers choose not to search as hard. A direct consequence of this is that output declines as the inflation rate increases: agents produce less in each trade (intensive margin) due to the lower real balances, and fewer trades take place (extensive margin) due to the reduction in search intensity. All this has interesting implications for the velocity of money, an observable which is closely related to search intensity according to the theory.

Using (4) and the bargaining solution, we can write velocity as

$$
\bar{e} \alpha(1 / \bar{e}) \frac{\int_{0}^{R(z)} \frac{c\left(q_{\varepsilon}^{*}\right)}{\phi} d G(\varepsilon)+\int_{R(z)}^{1} M d G(\varepsilon)}{M} .
$$

\footnotetext{
${ }^{14}$ There are several ways to ensure that the buyer's problem has a unique solution. We could focus on inflation rates close to the Friedman Rule $(\gamma=\beta)$. One can also make assumptions on primitives so that there is a unique positive solution to the first-order necessary conditions. For example, it is sufficient to assume $\psi^{\prime \prime \prime}>0$ and $\mathcal{S}^{\prime \prime \prime}(z) \mathcal{S}^{\prime}(z)-2 \mathcal{S}^{\prime \prime}(z)^{2}<0$.
} 
Letting $v^{*}=\int_{0}^{R} \frac{c\left(q_{\varepsilon}^{*}\right)}{z} \frac{d G(\varepsilon)}{G(R)}$, we can conveniently rewrite this expression as

$$
\mathcal{V}=\bar{e} \alpha(1 / \bar{e})\left\{G(R) v^{*}+[1-G(R)]\right\}
$$

This shows aggregate velocity as a weighted average of 1, velocity in all trades for which the buyer's cash constraint binds, and $v^{*}$, the average velocity of money in those trades with slack cash constraints. Since $v^{*}<1$, there are high and low velocity trades, namely those with binding and slack constraints respectively. The first thing to note is that if there were no idiosyncratic preference shock, that is if $\varepsilon=1$ with probability one, then the cash constraint would be binding in every trade implying $\mathcal{V}=\bar{e} \alpha(1 / \bar{e})=\zeta(\bar{e}, 1)$. In this case velocity would be increasing in average search intensity and hence (by Proposition 1) always decreasing in the rate of inflation.

On the other hand, for fixed search intensity, note that velocity rises when real balances fall. This happens for two reasons. First, when real balances fall, velocity increases in those trades with slack cash constraints: since real balances are lower, a buyer needs to spend a larger fraction of his cash holdings to buy the first-best quantity. And second, $R$ falls when $z$ falls and this increases the fraction of high velocity trades (i.e., the fraction of trades with binding constraints). In general, the effect of inflation on velocity is ambiguous. On the one hand inflation reduces real balances and this makes buyers search less intensively. This is the (negative) extensive-margin effect of inflation on velocity. On the other hand, higher inflation causes velocity to rise in low velocity trades and the proportion of these trades fall. This is the (positive) intensive-margin effect of inflation on velocity. The extensive and intensive margins move in opposite directions and the net effect is ambiguous in general.

Comparing (5) to (21) and (6) to (20), we see that the equilibrium with ex post bargaining is inefficient. Conditions (5) and (21) coincide if and only if $\gamma=\beta$. That is, the equilibrium achieves efficiency along the intensive margin under the Friedman Rule (agents exchange the efficient quantities in all trades). For the equilibrium to also achieve efficiency along the extensive margin (i.e., for search intensities to coincide), in addition we would need to have $\eta(1 / e)=1$. But since $\eta(1 / e) \in(0,1)$ for all $e$, buyers search excessively in the equilibrium.

We verify that the main results carry over to the case where the buyer's bargaining power is $\lambda \in(0,1)$. To ease the exposition, we now assume $\varepsilon=1$ in all matches, which implies the cash constraint will bind in every trade. The corresponding generalized Nash bargaining solution 
$\max _{q}[u(q)-z]^{\lambda}[z-c(q)]^{1-\lambda}$ implies $z=g_{\lambda}(q)$, where

$$
g_{\lambda}(q)=\frac{\lambda u^{\prime}(q) c(q)+(1-\lambda) u(q) c^{\prime}(q)}{\lambda u^{\prime}(q)+(1-\lambda) c^{\prime}(q)} .
$$

The equilibrium conditions are:

$$
\begin{aligned}
\frac{u^{\prime}(q)}{g_{\lambda}^{\prime}(q)} & =1+\frac{\gamma-\beta}{e \alpha(1 / e) \beta} \\
\psi^{\prime}(e) & =\alpha(1 / e)\left[u(q)-g_{\lambda}(q)\right] \\
u(q)-g_{\lambda}(q) & =\frac{\lambda u^{\prime}(q)}{\lambda u^{\prime}(q)+(1-\lambda) c^{\prime}(q)}[u(q)-c(q)] .
\end{aligned}
$$

For the case of $\lambda=1$ we analyzed before, (25) implies $z=g_{1}(q)=c(q)$. Figure 1 illustrates the determination of the equilibrium: panels (a) and (b) depict the equilibrium conditions for $\lambda=1$ and $\lambda \in(0,1)$ respectively. In both panels, the dotted lines represent the planner's first-order conditions

$$
\begin{aligned}
& \frac{u^{\prime}(q)}{c^{\prime}(q)}=1 \\
& \psi^{\prime}(e)=\alpha(1 / e) \eta(1 / e)[u(q)-c(q)] .
\end{aligned}
$$

The curve labeled $e^{*}(q)$ gives the optimal search intensity as a function of $q$ according to (27). The equilibrium pair $(e, q)$ is determined by the intersection of the $q(e ; \gamma)$ and the $e(q)$ loci which correspond to (23) and (24) respectively. Several results are immediate from the figure. First, for the case of $\lambda=1, q=q^{*}$ under the Friedman Rule and search intensity is inefficiently high. For the case of $\lambda \in(0,1)$, the curve $e(q)$ reaches a maximum at some $\tilde{q}<q^{*}$, and $q=\tilde{q}$ under the Friedman Rule. However, for general $\lambda$, it may no longer be the case that search intensity is too high under the Friedman Rule. ${ }^{15}$ Second, in both panels an increase in $\gamma$ shifts $q(e ; \gamma)$ upward causing $e$ and $q$ to decrease. Consequently inflation reduces aggregate output for any $\lambda \in(0,1]$. Proposition 2 establishes that welfare is decreasing in inflation if $\lambda=1$, but in fact this result generalizes to any $\lambda .{ }^{16}$

\footnotetext{
${ }^{15}$ The Hosios (1990) condition for efficiency in search economies is necessarily violated in our formulation with $\lambda=1$ : the buyer's bargaining power is larger than his share in the matching process, i.e., $\lambda=1>\eta(e)$. But for a general $\lambda$, search intensity may be inefficiently high or low under the Friedman Rule. See Berentsen, Rocheteau and Shi (2001) for a detailed treatment of these issues.

${ }^{16}$ The argument goes as follows. Welfare can be written as $e \alpha\left[u(q)-g_{\lambda}(q)\right]-\psi(e)+e \alpha\left[g_{\lambda}(q)-c(q)\right]$. Using (24) this becomes $e \psi^{\prime}(e)-\psi(e)+e \alpha\left[g_{\lambda}(q)-c(q)\right]$, which is increasing in $e$ and $q$ and hence decreasing in $\gamma$.
} 


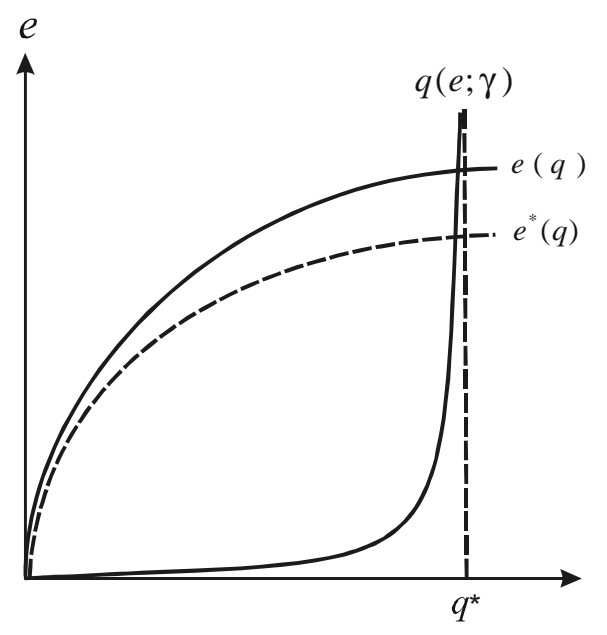

(a) $\lambda=1$

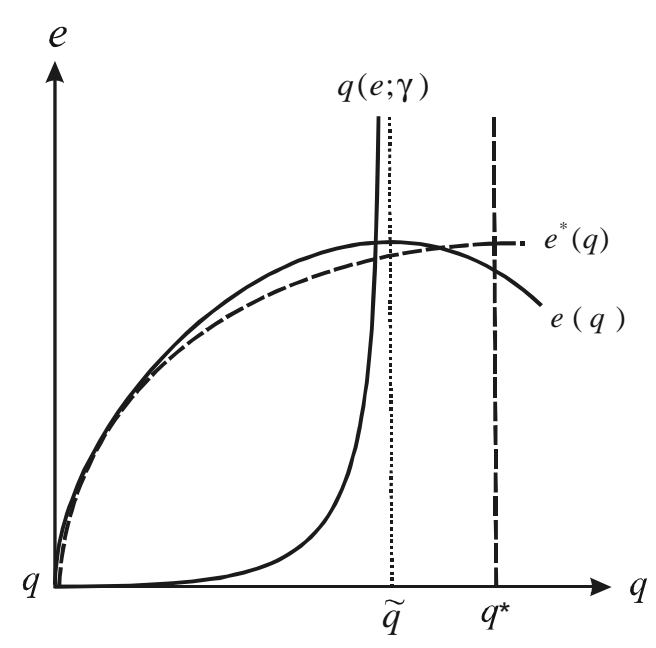

(b) $\lambda \in(0,1)$

Figure 1: Equilibrium with bargaining.

The normative and positive implications of the model are not in line with the conventional wisdom articulated by Lucas (2000), for instance. Lucas' view is that agents invest additional resources to get away from cash as the inflation rate increases, and that these resources are part of the welfare cost of inflation. But in the model with bargaining, agents always reduce their search effort if the inflation rate increases. If the buyer's bargaining power is large, e.g., if $\lambda=1$, then search costs are inefficiently high under the Friedman Rule, and higher inflation reduces those search costs bringing the extensive margin in the equilibrium closer to the efficient benchmark. All else constant, this effect has a positive impact on welfare. However, in equilibrium, this partial effect is outweighed by the distortion in the intensive margin caused by the reduction in real money balances. As a result, welfare unambiguously decreases with the rate of inflation.

\section{Competitive price posting}

In this section we adopt the notion of price posting with directed search proposed by Moen (1997) and Shimer (1996). We depart from the random matching assumption of the previous 
section and set up a decentralized market in which search can be partially directed. ${ }^{17}$ The sequencing is as follows. First, each buyer locates himself in one of possibly many distinct submarkets by credibly posting terms of trade at which he stands ready to trade with any seller he contacts. Each seller then directs her search toward a particular submarket, and once there, meets potential trading partners at random within the submarket. ${ }^{18}$ As before, the extent of the meeting frictions will depend on the number of sellers posting the same terms of trade and the number of buyers searching for these sellers. Both buyers and sellers form rational expectations about the market tightness on the different submarkets.

We define a submarket as a subset of buyers who post the same contract and randomly search for sellers with whom to trade at the terms of trade specified by this contract. Formally, a submarket is a triple $\mathrm{S}=\left[q\left(m_{s}\right), d\left(m_{s}\right), \theta\right]$ where $\left[q\left(m_{s}\right), d\left(m_{s}\right)\right]$ is the menu posted by buyers and at which both buyers and sellers commit to trade, if they choose to trade, and $\theta$ is the tightness of the submarket $\mathrm{s}$ that is generated by $(q, d)$. Note that terms of trade $(q, d)$ may in principle be contingent on sellers' money balances although sellers will not hold money in equilibrium. The choice of menu also depends on the buyer's own money holdings

\footnotetext{
${ }^{17}$ Moen (1997) suggests two interpretations for the notion of price posting equilibrium in this setup. In one, a "market maker" creates and separates the submarkets and determines the terms of trade in each. These terms of trade are in fact what distinguish submarkets: they are the same for all trades in a given submarket, but differ across submarkets. The fictitious market maker ensures that there is no submarket she could open that would make sellers better off without making buyers worse off. The second interpretation — the one we are adopting-is one of a decentralized market in which buyers (or sellers) post and commit to the terms of trade (which amounts to their choosing a submarket) and sellers (or buyers) choose what submarket to search in. This notion of equilibrium requires that the agents who announce the terms of trade be able to commit to their announcement. As is well known, money is inessential in environments in which agents have the ability to commit to any future actions. But the notion of commitment required by the notion of price posting equilibrium is rather weak; too weak to render money inessential. Here we provide two notions of partial commitment that are strong enough for the price posting equilibrium to make sense but weak enough so that money remains essential. First, in the setup in which sellers post prices, we can imagine that they can commit to any present or future action but buyers cannot. And second, in a similar spirit to the no-commitment mechanisms of Kocherlakota (1998), we can assume that when faced with any trade, an agent can always choose autarky.

${ }^{18}$ Here we follow Moen (1997) and let buyers post prices and sellers direct their search. This makes the comparison with the section on bargaining easier as under both pricing mechanisms buyers choose search intensity, real balances and terms of trade. It would be equivalent to define a submarket as a subset of sellers who post the same contract and a subset of buyers who randomly search for individual sellers offering this contract.
} 
$m_{b}$. To make the notation consistent with those of the previous section we use $q\left(m_{b}, m_{s}\right)$ to denote the quantity produced by the seller and consumed by the buyer, and $d\left(m_{b}, m_{s}\right)$ the money transfer from the buyer to the seller when their money balances are $m_{b}$ and $m_{s}$ respectively. We use $\theta(\mathrm{s})$ to denote the ratio of the measure of sellers to the measure of effective buyers searching in submarket s. Through the matching probabilities $\alpha_{b}=e \zeta[1, \theta(\mathrm{s})]$ and $\alpha_{s}=\zeta[1 / \theta(\mathrm{s}), 1]$, the "(sub)market tightness" $\theta(\mathrm{s})$ determines the expected waiting times to complete a trade for buyers and sellers in submarket $\mathrm{S}$. If there is a subset $A_{b}(\mathrm{~s}) \subseteq A_{b}$ of buyers and a subset $A_{s}(\mathrm{~s}) \subseteq A_{s}$ of sellers in submarket $\mathrm{s}$, with masses $\mu_{b}(\mathrm{~s})$ and $\mu_{s}(\mathrm{~s})$ respectively, then $\theta(\mathrm{s})=\frac{\mu_{s}(\mathrm{~s})}{\bar{e}(\mathrm{~s}) \mu_{b}(\mathrm{~s})}$ where $\bar{e}(\mathrm{~s})=\left[1 / \mu_{b}(\mathrm{~s})\right] \int_{A_{b}(\mathrm{~s})} e_{i} d i$. In this section we let $\alpha[\theta(\mathrm{s})] \equiv \zeta[1, \theta(\mathrm{s})]$, so we write $\alpha_{b}=e \alpha[\theta(\mathrm{s})]$ and $\alpha_{s}=\alpha[\theta(\mathrm{s})] / \theta(\mathrm{s})$. (We will omit the argument of $\alpha$ and $\alpha_{s}$ when no confusion may result.)

The problem of a seller holding $m$ dollars and searching for a buyer in submarket $\mathrm{s}=(q, d, \theta)$ when the price of money in terms of general goods in the next centralized market is $\phi$ is summarized by the following Bellman equation:

$$
V^{s}(m, \mathrm{~s}, \phi)=\alpha_{s}\left\{-c\left[q\left(m_{b}, m\right)\right]+W^{s}\left[m+d\left(m_{b}, m\right), \phi\right]\right\}+\left(1-\alpha_{s}\right) W^{s}(m, \phi),
$$

where $m_{b}$ is the money holdings of buyers in submarket $\mathrm{s}$. The lifetime expected utility of a seller entering the centralized market with $m$ dollars when the real price of a dollar is $\phi$ is denoted $W^{s}(m, \phi)$ and satisfies

$$
W^{s}(m, \phi)=\max _{\mathrm{s} \in \mathrm{S}} \hat{W}^{s}(m, \mathrm{~s}, \phi),
$$

where $\mathrm{S}$ is the set of all submarkets that are active, $\hat{m} \geq 0$, and $\hat{W}^{s}(m, \mathrm{~S}, \phi)$ satisfies

$$
\hat{W}^{s}(m, \mathrm{~s}, \phi)=\phi m+\max _{\hat{m}}\left[\beta V^{s}\left(\hat{m}, \mathrm{~s}, \phi_{+1}\right)-\phi \hat{m}\right] .
$$

Equations (28)-(29) state that sellers choose their money holdings and direct their search toward the submarket that maximizes their expected utility.

The value of search to a buyer holding $m$ units of money who has chosen to post terms of trade $(q, d)$ and hence to be in submarket $\mathrm{S}=(q, d, \theta)$ is given by:

$$
\begin{gathered}
V^{b}(m, \mathrm{~s}, \phi)=\max _{e}\left\{-\psi(e)+(1-\alpha e) W^{b}(m, \phi)\right. \\
\left.+\alpha e \int\left\{u[q(m, \tilde{m})]+W^{b}[m-d(m, \tilde{m}), \phi]\right\} d F^{s}(\tilde{m})\right\},
\end{gathered}
$$


where $F^{s}$ is the distribution of money holdings among sellers searching in submarket $\mathrm{S}$. The value of a buyer entering the centralized market with $m$ dollars is

$$
W^{b}(m, \phi)=\phi(m+T)+\max _{\hat{m}, \mathrm{~s}}\left[\beta V^{b}\left(\hat{m}, \mathrm{~s}, \phi_{+1}\right)-\phi \hat{m}\right]
$$

subject to $\theta \geq 0, \hat{m} \geq 0, d\left(\hat{m}, m^{s}\right) \leq \hat{m}$ for all $m_{s}$, and

$$
\hat{W}^{s}(0, \mathrm{~s}, \phi) \geq W^{s}(0, \phi) .
$$

The left side of (31) is the expected utility of a seller who chooses to search in submarket $\mathrm{s}$, and the right side is the expected utility from searching in the submarket that maximizes her expected utility. Note that condition (31) ensures that sellers who carry no money are just as well off searching in submarket $\mathrm{s}$ as elsewhere. But $\hat{W}^{s}\left(m^{s}, \mathrm{~s}, \phi\right)-W^{s}\left(m^{s}, \phi\right)$ is independent of $m^{s}$, so if (31) holds for $m^{s}=0$ (which will be the case in equilibrium), then it holds for any $m^{s}$. This condition defines an implicit relationship between $\theta$, the terms of trade $(q, d)$ and $W^{s}(0, \phi)$, and says that a submarket receives sellers only if it offers them the maximum level of expected utility they can achieve by searching in another submarket. Submarkets for which (31) does not hold do not attract sellers and therefore are inactive.

\subsection{Prices}

As in the previous sections, we specialize the analysis to stationary equilibria in which $M_{+1} / M=$ $\phi / \phi_{+1}=\gamma>\beta$. The terms of trade $(q, d)$ are posted by buyers, so to see how they are determined we take a closer look at their maximization problem in the decentralized market. First note that since $W^{b}(m, \phi)=W^{b}(0, \phi)+\phi m$, the value function $V^{b}$ can be written as

$$
V^{b}(m, \mathrm{~s}, \phi)=\max _{e}\left[\alpha e \mathcal{S}_{b}\left(m, F^{s}, \phi\right)-\psi(e)+W^{b}(0, \phi)+\phi m\right],
$$

where $\mathcal{S}_{b}\left(m, F^{s}, \phi\right) \equiv \int\{u[q(m, \tilde{m})]-\phi d(m, \tilde{m})\} d F^{s}(\tilde{m})$ is the buyer's expected surplus from trade, and $e$ is constrained to be nonnegative. Substituting this expression into (30) we get

$$
W^{b}(m, \phi)=\phi(m+T)+\beta W^{b}\left(0, \phi_{+1}\right)+\beta \max _{\hat{m}, \mathrm{~S}, e}\left[\alpha e \mathcal{S}_{b}\left(\hat{m}, F^{s}, \phi_{+1}\right)-\psi(e)-\left(\frac{\gamma}{\beta}-1\right) \phi_{+1} \hat{m}\right],
$$

where the maximization is subject to $\theta \geq 0, \hat{m} \geq 0, e \geq 0, d(\hat{m}, \tilde{m}) \leq \hat{m}$ for all $\tilde{m}$, and (31). Similarly for sellers, $W^{s}(m, \phi)=W^{s}(0, \phi)+\phi m$ and therefore

$$
V^{s}(m, \mathrm{~s}, \phi)=\alpha_{s} \mathcal{S}_{s}\left(m_{b}, m, \phi\right)+\phi m+W^{s}(0, \phi) .
$$


where $\mathcal{S}_{s}\left(m_{b}, m, \phi\right) \equiv \phi d\left(m_{b}, m\right)-c\left[q\left(m_{b}, m\right)\right]$ is the seller's surplus. Substituting this expression in (29) yields

$$
\hat{W}^{s}(m, \phi)=\phi m+\beta W^{s}\left(0, \phi_{+1}\right)+\beta \max _{\hat{m}}\left[\alpha_{s} \mathcal{S}_{s}\left(m_{b}, \hat{m}, \phi_{+1}\right)-\left(\frac{\gamma}{\beta}-1\right) \phi_{+1} \hat{m}\right] .
$$

Therefore the buyer's problem in the centralized market is

$$
\max _{\hat{m}, S, e}\left[\alpha e \mathcal{S}_{b}\left(\hat{m}, F^{s}, \phi_{+1}\right)-\psi(e)-\left(\frac{\gamma}{\beta}-1\right) \phi_{+1} \hat{m}\right],
$$

with $\mathrm{S} \equiv[q(\hat{m}, \tilde{m}), d(\hat{m}, \tilde{m}), \theta]$ and subject to $\theta \geq 0, \hat{m} \geq 0, e \geq 0, d(\hat{m}, \tilde{m}) \leq \hat{m}$ for all $\tilde{m}$, and

$$
\max _{\hat{m}}\left[\alpha_{s} \mathcal{S}_{s}\left(m_{b}, \hat{m}, \phi_{+1}\right)-\left(\frac{\gamma}{\beta}-1\right) \phi_{+1} \hat{m}\right] \geq U^{s}
$$

where

$$
U^{s} \equiv \max _{\mathrm{S} \in S, \hat{m}}\left[\alpha_{s} \mathcal{S}_{s}\left(m_{b}, \hat{m}, \phi_{+1}\right)-\left(\frac{\gamma}{\beta}-1\right) \phi_{+1} \hat{m}\right] .
$$

So, the buyer maximizes his expected surplus in the search market net of the search cost and the cost of carrying real balances, and subject to the constraint that the contract he chooses satisfies sellers' participation constraint. The following lemma summarizes the main properties of the solutions to the individual decision problems.

Lemma 3 (a) Sellers carry no cash into the decentralized market.

(b) The buyer's optimal choices are described by the following correspondence:

$$
\Upsilon\left(U^{s}\right)=\arg \max _{q, z, \theta, e}\left\{e \alpha(\theta)[u(q)-z]-\psi(e)-\left(\frac{\gamma}{\beta}-1\right) z\right\},
$$

subject to $q, z, e \geq 0$ and $\theta \geq 0$ if $\alpha_{s}(\theta)[z-c(q)] \geq U^{s}$ or $\theta=0$ otherwise.

(c) $\Upsilon\left(U^{s}\right)$ is nonempty and upper-hemi continuous.

Sellers have no use for money in the decentralized market, so as long as $\gamma>\beta$, they choose $m^{s}=0$ in the centralized market. The buyer's objective function in part (b) is identical to (19), that of a buyer under bargaining. We can think of the buyer's problem as one of choosing search intensity and a simple contract $(q, z)$ specifying a level of real balances $z$ that he will carry into the submarket and will hand over to any seller he meets in exchange for $q$ units of output. In principle, different buyers may choose to operate in different submarkets by offering 
different $(q, z)$ pairs. If this is the case, sellers then choose which submarket to search in. The participation condition for sellers can be used to solve for the submarket tightness, $\theta$, implied by any combination of terms of trade $(q, z)$ offered in the submarket and any market-wide utility level $U^{s}$. Observe that if the submarket is active then the participation condition for sellers will bind at the optimum (else the contract posted by the buyer would fail to maximize his utility), so $\alpha_{s}(\theta)[z-c(q)]=U^{s}$. Part (c) establishes that the buyer's problem has a solution and that the solution(s) would vary continuously with $U^{s}$.

\subsection{Equilibrium}

We are now ready to define the notion of equilibrium we employ in this section.

Definition 2 Given a money supply process $M_{+1} / M=\gamma$, a stationary competitive price posting monetary equilibrium is a sequence $\left\{\phi_{t}, Z_{t}\right\}$ with $Z_{t}=Z$ for all $t$ and a collection $\left\{U^{b}, U^{s},\left(q_{i}, z_{i}, e_{i}, \theta_{i}\right)_{i \in[0,1]}\right\}$ such that:

(C1) Given $U^{s},\left(q_{i}, z_{i}, \theta_{i}, e_{i}\right) \in \Upsilon\left(U^{s}\right)$

(C2) $\int_{[0,1]} e_{i} \theta_{i} d i=1$

(C3) $\int_{[0,1]} z_{i} d i=Z$

(C4) $\phi_{t}=\frac{Z}{M_{t}}$

(C5) $U^{b}=e_{i} \alpha\left(\theta_{i}\right)\left[u\left(q_{i}\right)-z_{i}\right]-\psi\left(e_{i}\right)-\left(\frac{\gamma}{\beta}-1\right) z_{i}, \quad$ for $\left(q_{i}, z_{i}, \theta_{i}, e_{i}\right) \in \Upsilon\left(U^{s}\right)$

Consistent with Lemma 3, (C1) says that the allocation $\left(q_{i}, z_{i}, \theta_{i}, e_{i}\right)$ must be an equilibrium of the price posting game. Condition (C2) is an aggregate consistency condition: it states that the numbers of buyers and sellers each add up to 1 . We can also think of this condition as stating that the aggregate demand for sellers (the left-hand side of (C2)) must equal the aggregate supply, i.e., 1. Under this interpretation (C2) determines $U^{s}$, the "price of a seller" that clears the market for sellers. ${ }^{19}$ (C3) is the clearing condition for the money market. (C4)

\footnotetext{
${ }^{19}$ Recall that a submarket $\mathrm{S}$ is essentially defined by a set of buyers each choosing the same tuple $(q(\mathrm{~s}), z(\mathrm{~s}), e(\mathrm{~s}), \theta(\mathrm{s}))$. That is, $\left(q_{i}, z_{i}, e_{i}, \theta_{i}\right)=(q(\mathrm{~s}), z(\mathrm{~s}), e(\mathrm{~s}), \theta(\mathrm{s}))$ for each buyer $i \in A_{b}(\mathrm{~s})$. Since we are assuming that $\mu_{b}=\mu_{s}=1$, i.e., that the total numbers of buyers and sellers each equals one, the equilibrium
} 
maps real balances and the money supply into the reciprocal of the price level. (C5) simply defines $U^{b}$ as the maximum value of the buyer's program. The following proposition states that a monetary equilibrium exists as long as the inflation rate $\gamma$ is not too high.

Proposition 3 A stationary competitive price posting monetary equilibrium exists if

$$
\max _{q, z, e}\left\{e[u(q)-c(q)]-\psi(e)-\left(\frac{\gamma}{\beta}-1\right) c(q)\right\}>0 .
$$

Given $U^{s}$, in any active submarket $\mathrm{s}$ the contract $(q, z)$, the tightness $\theta$ and the buyer's search intensity $e$ must satisfy:

$$
\begin{aligned}
\frac{u^{\prime}(q)}{c^{\prime}(q)} & =1+\frac{\gamma-\beta}{e \alpha(\theta) \beta} \\
\psi^{\prime}(e) & =\alpha(\theta)[u(q)-z] \\
u(q)-z & =\frac{\eta(\theta) u^{\prime}(q)}{\eta(\theta) u^{\prime}(q)+[1-\eta(\theta)] c^{\prime}(q)}[u(q)-c(q)] \\
U^{s} & =\alpha_{s}(\theta)[z-c(q)] .
\end{aligned}
$$

Equations (32), (33) and (34) are the first-order conditions of the buyer's problem for $q$, $e$ and $\theta$ respectively. ${ }^{20}$ Just as in the previous section, (32) defines a relationship between $q$ and the buyer's probability of trade, $e \alpha$. The higher the probability of trade, the larger the real balances the buyer will carry. And more real balances translate into larger quantities traded of the search good. Condition (33) defines the equilibrium level of search intensity as the one that equates the marginal cost of search to the marginal increase in the buyer's expected gain from trade. Condition (34) comes from the choice of market tightness and defines the gain from trade that accrues to the buyer: $u(q)-z=\omega(\theta, q)[u(q)-c(q)]$, where $\omega(\theta, q) \equiv \frac{\eta(\theta) u^{\prime}(q)}{\eta(\theta) u^{\prime}(q)+[1-\eta(\theta)] c^{\prime}(q)}$ is the buyer's share of the total surplus.

In what follows we focus on equilibria where the buyer's problem has a unique solution and hence a single submarket is active. This, for example, is the case for inflation rates close to allocation must satisfy $\sum_{\mathrm{s} \in \mathrm{S}} \mu_{s}(\mathrm{~S})=\sum_{\mathrm{s} \in \mathrm{S}} \mu_{b}(\mathrm{~s})=1$. Because market tightness in submarket $\mathrm{s}$ was defined as $\theta(\mathrm{s})=\frac{\mu_{s}(\mathrm{~s})}{e(\mathrm{~s}) \mu_{b}(\mathrm{~s})}$, this aggregate consistency condition can be written as $\sum_{\mathrm{s} \in \mathrm{S}} \mu_{b}(\mathrm{~s}) \theta(\mathrm{s}) e(\mathrm{~s})=1$. And since $\mu_{b}(\mathrm{~s})=\int_{A_{b}(\mathrm{~s})} d i$ and $(e(\mathrm{~s}), \theta(\mathrm{s}))=\left(e_{i}, \theta_{i}\right)$ for all $i \in A_{b}(\mathrm{~s})$, we can write the condition as $\sum_{\mathrm{s} \in \mathrm{S}} \int_{A_{b}(\mathrm{~s})} \theta_{i} e_{i} d i=1$, or $\int_{[0,1]} \theta_{i} e_{i} d i=1$ since $\cup_{\mathrm{s} \in \mathrm{S}} A_{b}(\mathrm{~s})=[0,1]$, which is (C2). This condition is analogous to the equilibrium condition for " $\lambda$ " in Lucas and Prescott (1974).

${ }^{20}$ The corresponding Lagrangian is $\mathcal{L}^{b}=e \alpha(\theta)[u(q)-z]-\psi(e)-(\gamma / \beta-1) z+\rho^{s}\left\{(1 / \theta) \alpha(\theta)[z-c(q)]-U^{s}\right\}$, where $\rho^{s}$ is the shadow price of the seller's participation constraint. 
the Friedman Rule (see Lemma 4 in the Appendix). When the buyer's problem has a unique solution, (C2) simplifies to $\theta=1 / e$ and (C3) to $z=Z$. Conditions (32)-(34) can be solved for $(q, z, e)$; given $e$ we know $\theta$ and (35) yields $U^{s}$. This allows us to rewrite (32) and (33) as

$$
\begin{aligned}
\frac{u^{\prime}(q)}{c^{\prime}(q)} & =1+\frac{\gamma-\beta}{e \alpha(1 / e) \beta} \\
\psi^{\prime}(e) & =\alpha(1 / e) \frac{\eta(1 / e) u^{\prime}(q)}{\eta(1 / e) u^{\prime}(q)+[1-\eta(1 / e)] c^{\prime}(q)}[u(q)-c(q)] .
\end{aligned}
$$

From (36) it is immediate that the Friedman Rule implies $q=q^{*}$ and hence achieves efficiency along the intensive margin. Also, when $\gamma=\beta,(37)$ is identical to (6) for the case with $\varepsilon=1$ with

probability 1 . Thus under competitive price posting the Friedman Rule also achieves efficiency along the extensive margin: it induces efficient search intensity. The following proposition summarizes the effects of inflation on the intensive margin, welfare, and search intensity under competitive price posting.

Proposition 4 The equilibrium is efficient under the Friedman Rule. Inflation reduces $q$, and deviations from the Friedman Rule reduce welfare. For $\gamma$ close to $\beta$ an increase in $\gamma$ increases search intensity $e$.

\subsection{Discussion}

The determination of the equilibrium is illustrated in Figure 2. The dotted lines represent the planner's first-order conditions (26) and (27). The $(q, e)$ combinations that satisfy (36) lie on the curve labeled $q(e ; \gamma)$. The $(q, e)$ pairs that satisfy $(37)$ lie on the curve labeled $e(q)$. Note that $q(e ; \beta)=q^{*}$ and $e\left(q^{*}\right)=e^{*}\left(q^{*}\right)$, so the Friedman Rule induces efficient production and search intensity decisions. As in the model with bargaining, inflation shifts up the $q(e ; \gamma)$ locus and always reduces $q$. The effect of inflation on search intensity depends on the level of $\gamma$. For high $\gamma$, an increase in inflation induces buyers to reduce search intensity e. For low $\gamma$, buyers raise their search intensity in response to an increase in inflation. The key to a positive extensive margin effect lies in the non-monotonic relationship between $e$ and $q$ defined by (33), namely

$$
\psi^{\prime}(e)=\alpha(1 / e) \omega(1 / e, q)[u(q)-c(q)]
$$




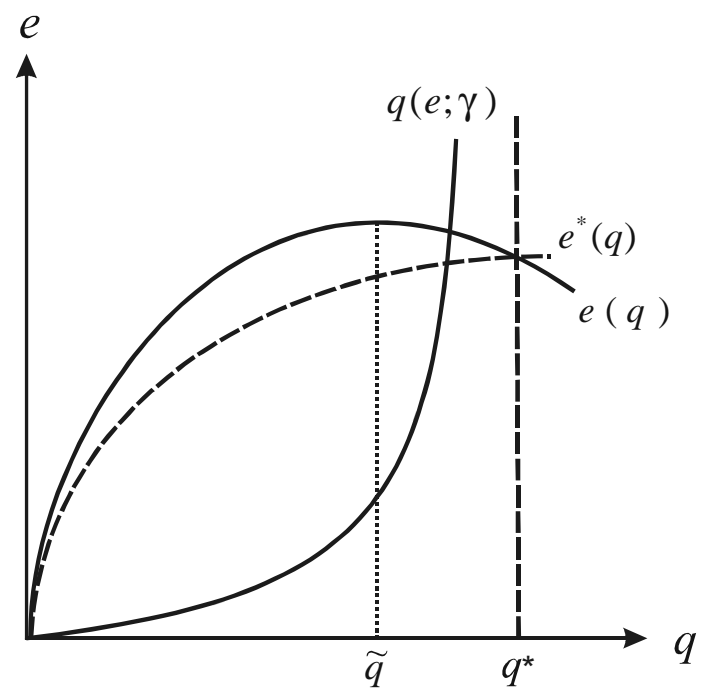

Figure 2: Equilibrium under competitive price posting

The right side represents the buyer's expected gains from trade in the search market. It is convenient to think of this gain as the product of two factors: the total surplus, $u(q)-c(q)$, and the buyer's share of this surplus, $\omega$. The total surplus is increasing in $q$ ("the total surplus effect"), but notice that the buyer's share is decreasing in the size of the trade, $q$ (the "share effect"). Intuitively, as $q$ increases, the marginal utility of a buyer falls relative to the marginal disutility from production incurred by the seller and therefore equating their marginal utilities from trade, which requires the buyer to get a smaller share of the total surplus. The net effect on the buyer's expected gains from trade can go either way and this causes the relationship between $e$ and $q$ to be non-monotonic. For small $q$ the surplus is steep so the "total surplus effect" dominates and the buyer's gain from trade is increasing in $q$. The "share effect" dominates for large $q$ and consequently the buyer's gain from trade is decreasing in the size of the trade, $q$, beyond some threshold $\tilde{q}<q^{*}$. Suppose, for example, that the inflation rate increases slightly from $\gamma=\beta$. The quantity $q$ falls slightly below $q^{*}$, but since $u(q)-c(q)$ is maximized at $q^{*}$, the total surplus suffers only a second order reduction. The buyer's share $\omega(1 / e, q)$ will experience a first-order increase and as a result the buyer's expected gain from trade will rise and this will induce him to increase his search intensity. ${ }^{21}$

\footnotetext{
${ }^{21}$ A similar non-monotonic relationship between $e$ and $q$ is obtained from the model with generalized Nash
} 
The economic reasoning behind the non-monotonic relationship between $e$ and $\gamma$ deserves further attention. The distinctive feature of competitive price posting is that price-setters compete for trading probabilities. They internalize both congestion and thick market effects, which is precisely why the equilibrium allocation is efficient at $\gamma=\beta$. As $\gamma$ increases, buyers reduce their real balances and this reduces the match surplus $u(q)-c(q)$. If the buyer's share of this surplus was to remain constant, the buyer's expected gains from trade falls and so does his willingness to pay for a contact with a seller. For the market for contact probabilities to clear, the "price" $U^{s}$ needs to adjust downward. The reduction in $U^{s}$ occurs in equilibrium through a fall in the seller's share. A similar story can be told for the case in which sellers are the ones who post prices. As inflation increases, buyers will tend to carry lower real balances into the decentralized market. To encourage buyers to bring more cash (in order to increase the gains of trade $u(q)-c(q)$ of the buyer-seller match) sellers offer them a better deal, i.e., a larger share of the surplus.

An increase in inflation always has a negative intensive margin effect on output: less output is traded in each match. Furthermore, for high inflation, the number of trades falls so the extensive margin effect of inflation on output is also negative. Thus for high $\gamma$, aggregate output unambiguously falls with inflation. At low inflation rates, however, the frequency of trades is increasing in the rate of inflation. Therefore, if the positive extensive margin effect dominates the negative intensive margin effect then total output will rise. We parametrized the model, computed several examples, and found that the positive effects of inflation on output can be large. For example, suppose $\alpha(1 / e)=[1-\exp (-\varepsilon / e)], u(q)=\frac{(q+b)^{1-\sigma}-b^{1-\sigma}}{1-\sigma}, \psi(s)=$ $A e^{\rho}(1-e)^{-\rho}$, and $c(q)=q^{\kappa} / \kappa$. When $\beta=.99, \varepsilon=.01, \sigma=.7, b \approx 0, \rho=1.2, A=1$ and $\kappa=25$, going from the Friedman Rule (which corresponds to a $1 \%$ deflation) to price stability entails a $5 \%$ increase in aggregate output. Increasing inflation further from 0 to $1 \%$ implies an additional output gain of $1.4 \%$. Output peaks at around $6 \%$ inflation, and at that point aggregate output is about $7.6 \%$ higher than it would be under the Friedman Rule. ${ }^{22}$

bargaining in which the seller has bargaining power. However, as we showed in the previous section, the equilibrium $(q, e)$ pair of the model with generalized Nash bargaining will never lie on the downward sloping part of the schedule that $(24)$ and $(25)$ define in $(q, e)$ space. (See Figure 1.) Therefore search intensity (and hence velocity and aggregate output) always fall with inflation in the model with bargaining.

${ }^{22}$ The intensive margin is less responsive to inflation if $c(q)$ is very convex, so the size of the output effect is increasing in $\kappa$. For instance if $\kappa=15$, output is $2.7 \%$ higher at $0 \%$ inflation than at the Friedman rule. The 
Interestingly, this model is consistent with the common wisdom on the welfare effects of anticipated inflation we discussed in the introduction. An increase in inflation can induce agents to spend additional resources to try to get rid of their cash and these additional resources spent are a social waste. The model is also broadly consistent with the recent empirical evidence on the long-run output effects of permanent changes in inflation of Bullard and Keating (1995).

\section{Conclusion}

It is only natural for economic agents to devote more effort to trading away their cash holdings at higher inflation rates. But ultimately, money has to be held by someone, so these efforts are bound to be socially wasteful. Such is the conventional wisdom as captured by the quote from Lucas (2000) in our introduction. The actions taken in response to the inflation tax are also likely to have an impact on macroeconomic outcomes. Indeed, recent evidence seems to indicate that permanent increases in inflation are associated with permanent increases in the level of output in countries with low average inflation. We constructed two versions of a search-based model of monetary exchange and used them to study if, or under what conditions, the conventional wisdom regarding the changes in trading behavior in the face of inflation is supported by theory. We also explored its implications for the effects that permanent changes in the rate of inflation have on the level of output and on welfare.

We first considered the canonical search model of money in which prices are set according to ex post bilateral Nash bargaining between a buyer and a seller. We found that higher inflation always decreases search effort, the frequency of trades, and aggregate output. These implications are not in line with the conventional wisdom, say as articulated by Lucas (2000), and do not help us understand the nonlinear relationship between the anticipated rate of inflation and the level of output reported in Bullard (1999). From a normative point of view, ex post bargaining generically implements inefficient equilibria, and any deviation from the Friedman rule reduces welfare.

We then analyzed the model under competitive price posting and found that search intensity

extensive margin is more responsive if $\rho$ is small $(A \mathrm{big})$, so the output effect is larger for smaller (bigger) $\rho(A)$. For example, if we set $A=1.5$, then going from the Friedman Rule to price stability yields a $6.8 \%$ increase in aggregate output. 
and the frequency of trades increase with inflation at low inflation rates. When this extensive margin effect is strong enough, it is possible to have aggregate output increasing with anticipated inflation at low inflation rates but decreasing at high inflation rates. Thus, this version of the model can rationalize the conventional wisdom regarding the changes in agent's trading behavior in response to inflation, and at the same time help explain the nonlinear relationship between inflation and the level of output reported in Bullard (1999). Although it may be possible to increase output by running a mild inflation, inflating in excess of the Friedman Rule always reduces welfare. 


\section{Appendix A}

Proof of Lemma 1. (a) Using the bargaining solution (15) together with the fact that $c\left[q_{\varepsilon}(z)\right]=z$ in all matches, we rewrite the value functions in terms of real balances:

$$
\begin{aligned}
V^{b}(z) & =\max _{e \geq 0}\left[\alpha e \mathcal{S}(z)-\psi(e)+W^{b}(z)\right] \\
W^{b}(z) & =z+\tau+\max _{\hat{z} \geq 0}\left[\beta V^{b}(\hat{z})-\gamma \hat{z}\right] \\
V^{s}(z) & =W^{s}(z) \\
W^{s}(z) & =z+\max _{\hat{z}_{s} \geq 0}\left[\beta V^{s}\left(\hat{z}_{s}\right)-\gamma \hat{z}_{s}\right]
\end{aligned}
$$

It can easily be checked from (40) and (41) that $\hat{z}_{s}=0$ for all $\gamma>\beta$. This gives the first part of the Lemma. (b) Combine (38) and (39) and write

$$
V^{b}(z)=g(z)+z+\max _{\hat{z} \geq 0}\left[\beta V^{b}(\hat{z})-\gamma \hat{z}\right]
$$

Since $g$ is continuous and bounded (See proof of Lemma 2), we can use standard dynamic programming to establish the existence and uniqueness of a $V^{b}(z)$ that solves (42). ${ }^{23}$ By substituting the expressions in the statement of the lemma into (38) and (39) it is easy to see that they indeed solve the Bellman equations.

Proof of Lemma 2. (a) Our assumptions on primitives imply that $\alpha e \mathcal{S}(z)-\psi(e)$ is strictly concave in $e$, so the first order condition (20) is necessary and sufficient. It is immediate from this that $e(z)=\mathcal{S}(z)=0$ if $z=0$. The fact that $e(z)<1$ for all $z$ follows from our assumption that $\lim _{e \rightarrow 1} \psi^{\prime}(e)=+\infty$. Let $z_{1}^{*} \equiv c\left(q_{1}^{*}\right)$. Note that $\mathcal{S}^{\prime}(z)=\int_{R(z)}^{1}\left[\frac{\varepsilon u^{\prime}\left(q_{\varepsilon}\right)}{c^{\prime}\left(q_{\varepsilon}\right)}-1\right] d G(\varepsilon)$, so $\mathcal{S}^{\prime}(z)>0$ for all $z \in\left[0, z_{1}^{*}\right)$ and $\mathcal{S}^{\prime}(z)=0$ for all $z \geq z_{1}^{*}$, since $\mathcal{S}(z)=\mathcal{S}^{*}$ for all $z \geq$ $z_{1}^{*}$. Therefore, $e^{\prime}(z)=\frac{\alpha \mathcal{S}^{\prime}(z)}{\psi^{\prime \prime}(e)}>0$ for all $z \in\left[0, z_{1}^{*}\right)$ and $e^{\prime}(z)=0$ for all $z \geq z_{1}^{*}$, so the buyer's optimal choice of search intensity is increasing in his real money balances. (b) Let $\Delta(z ; \bar{e}, \gamma) \equiv \beta g(z)+(\beta-\gamma) z$. In the centralized market, buyers choose their demand for real balances by solving $\max _{z \geq 0} \Delta(z ; \bar{e}, \gamma)$. Observe that $\Delta_{1}(z ; \bar{e}, \gamma)=\beta \alpha e(z) \mathcal{S}^{\prime}(z)-(\gamma-\beta)$, so from part (a) we have $\Delta_{1}(z ; \bar{e}, \gamma)=-(\gamma-\beta)<0$ for all $z \geq z_{1}^{*}$. Thus we can write

\footnotetext{
${ }^{23}$ See Lemma 7 in Lagos and Wright (2002) for details.
} 
$\max _{z \geq 0} \Delta(z ; \bar{e}, \gamma)=\max _{z \in\left[0, z_{1}^{*}\right]} \Delta(z ; \bar{e}, \gamma)$. The buyer is maximizing a continuous function over a compact set. By the Theorem of the Maximum (e.g., Stokey and Lucas [1989], page 62) the correspondence $D:[0, \infty) \times[\beta, \infty) \rightarrow\left[0, z_{1}^{*}\right]$ defined by $D(\bar{e}, \gamma)=\underset{z \geq 0}{\arg \max } \Delta(z ; \bar{e}, \gamma)$ is nonempty, compact-valued and upper-hemi continuous. We know that $D(\bar{e}, \gamma) \subseteq\left[0, z_{1}^{*}\right)$ because $\Delta_{1}\left(z_{1}^{*} ; \bar{e}, \gamma\right)<0$. Next, we establish the comparative static results. The correspondence $D(\bar{e}, \gamma)$ is decreasing in $(\bar{e}, \gamma)$ if $\left(\bar{e}^{\prime \prime}, \gamma^{\prime \prime}\right) \succ\left(\bar{e}^{\prime}, \gamma^{\prime}\right), z^{\prime} \in D\left(\bar{e}^{\prime}, \gamma^{\prime}\right)$, and $z^{\prime \prime} \in D\left(\bar{e}^{\prime \prime}, \gamma^{\prime \prime}\right)$, then $z^{\prime \prime} \leq z^{\prime}$ (and $z^{\prime \prime}<z^{\prime}$ if $z^{\prime \prime}>0$ ), where " $\succeq$ " denotes the pairwise ordering relation on $\mathbb{R}^{2}$. The choice set $\left[0, z_{1}^{*}\right]$ is independent of $(\bar{e}, \gamma)$. Note that $\Delta_{13}(z ; \bar{e}, \gamma)=-1<0$, and that $\Delta_{12}(z ; \bar{e}, \gamma)=$ $\beta\left[e+\frac{\alpha \mathcal{S}(z)}{\psi^{\prime \prime}(e)}\right] \mathcal{S}^{\prime}(z) \alpha^{\prime}(\bar{e})<0$. Thus the objective function has strictly decreasing differences in $(\bar{e}, \gamma)$; i.e. for all $\left(\bar{e}^{\prime \prime}, \gamma^{\prime \prime}\right) \succ\left(\bar{e}^{\prime}, \gamma^{\prime}\right)$ we have $\Delta\left(z ; \bar{e}^{\prime \prime}, \gamma^{\prime \prime}\right)-\Delta\left(z ; \bar{e}^{\prime}, \gamma^{\prime}\right)<\Delta\left(\tilde{z} ; \bar{e}^{\prime \prime}, \gamma^{\prime \prime}\right)-\Delta\left(\tilde{z} ; \bar{e}^{\prime}, \gamma^{\prime}\right)$ if $z>\tilde{z}$. (See Topkis [1998].) We now show that $\left(\bar{e}^{\prime \prime}, \gamma^{\prime \prime}\right) \succ\left(\bar{e}^{\prime}, \gamma^{\prime}\right)$ implies $z^{\prime \prime} \leq z^{\prime}$. Suppose to the contrary that $z^{\prime \prime}>z^{\prime}$, then

$$
0 \leq \Delta\left(z^{\prime \prime} ; \bar{e}^{\prime \prime}, \gamma^{\prime \prime}\right)-\Delta\left(z^{\prime} ; \bar{e}^{\prime \prime}, \gamma^{\prime \prime}\right)<\Delta\left(z^{\prime \prime} ; \bar{e}^{\prime}, \gamma^{\prime}\right)-\Delta\left(z^{\prime} ; \bar{e}^{\prime}, \gamma^{\prime}\right) \leq 0
$$

a contradiction. So we conclude that $z^{\prime \prime} \leq z^{\prime}{ }^{24}$ Next, we show that if $z^{\prime \prime}>0$, then $\left(\bar{e}^{\prime \prime}, \gamma^{\prime \prime}\right) \succ$ $\left(\bar{e}^{\prime}, \gamma^{\prime}\right)$ implies $z^{\prime \prime}<z^{\prime}$. Since $z^{\prime \prime} \leq z^{\prime}, z^{\prime \prime}>0$ implies $z^{\prime}>0$ so $z^{\prime \prime}$ and $z^{\prime}$ must satisfy the first order necessary conditions $\Delta_{1}\left(z^{\prime \prime} ; \bar{e}^{\prime \prime}, \gamma^{\prime \prime}\right)=\Delta_{1}\left(z^{\prime} ; \bar{e}^{\prime}, \gamma^{\prime}\right)=0$. Suppose that $z^{\prime \prime}=z^{\prime}$, then since $\Delta(z ; \bar{e}, \gamma)$ has strictly decreasing differences in $(\bar{e}, \gamma)$, we have $0=\Delta_{1}\left(z^{\prime} ; \bar{e}^{\prime}, \gamma^{\prime}\right)>$ $\Delta_{1}\left(z^{\prime} ; \bar{e}^{\prime \prime}, \gamma^{\prime \prime}\right)=\Delta_{1}\left(z^{\prime \prime} ; \bar{e}^{\prime \prime}, \gamma^{\prime \prime}\right)=0$, a contradiction. Therefore $z^{\prime \prime}<z^{\prime}$.

Proof of Proposition 1. By Corollary 2.7.1 in Topkis (1998), we know that $D(\bar{e}, \gamma)$ has a greatest and a least element. Denote them $z_{H}(\bar{e})$ and $z_{L}(\bar{e})$ respectively. Then define a correspondence $E:[0, \infty) \times[\beta, \infty) \rightarrow[0, \infty)$ by

$$
E(\bar{e} ; \gamma)=\left\{e \in \mathbb{R}: e=\sigma h\left[z_{H}(\bar{e}), \bar{e}\right]+(1-\sigma) h\left[z_{L}(\bar{e}), \bar{e}\right] \text { for some } \sigma \in[0,1]\right\}
$$

So $E(\bar{e} ; \gamma)$ is the set of average search intensities resulting from all convex combinations of the elements of $D(\bar{e}, \gamma)$. The equilibrium condition $\int_{[0,1]} e(i) d i=\bar{e}$ can be reformulated as $\bar{e} \in E(\bar{e} ; \gamma)$, i.e., for given $\gamma, \bar{e}$ is a fixed point of the correspondence $E(\bar{e} ; \gamma)$. The correspondence $E(\bar{e} ; \gamma)$ is upper-hemi continuous and convex-valued. From (20), we see that $\bar{e} \rightarrow \infty$ implies $\alpha(\bar{e}) \rightarrow 0$, and hence $h\left[z_{i}(\bar{e}), \bar{e}\right] \rightarrow 0$ for $i=H, L$. (To see this, note that $\mathcal{S}(z) \leq \mathcal{S}^{*}<\infty$.)

\footnotetext{
${ }^{24}$ This argument resembles Theorem 2.8.4 in Topkis (1998).
} 
As $\bar{e} \rightarrow 0, \alpha(\bar{e}) \rightarrow 1$ and the buyer's maximization problem in the centralized market becomes $\max \{\beta[e \mathcal{S}(z)-\psi(e)]+(\beta-\gamma) z\}$ subject to $e \geq 0$ and $z \geq 0$. Since the value of setting $z=e=0$ is 0 , the condition $\max \{\beta[e \mathcal{S}(z)-\psi(e)]+(\beta-\gamma) z\}>0$ implies $z_{L}(0)>0$ and then from $(20)$ we have $h\left[z_{L}(0), 0\right]>0$. Thus a monetary equilibrium exists if $\max _{e \geq 0, z \geq 0}$ $\{\beta[e \mathcal{S}(z)-\psi(e)]+(\beta-\gamma) z\}>0$. (The only if part is immediate from the monotonicity of the equilibrium correspondence in $\bar{e}$, which we establish below.) From (20) and the comparative static results in parts (a) and (c) of Lemma 2 we know that $E(\bar{e} ; \gamma)$ is strictly decreasing in $\bar{e}$ so there is a unique $\bar{e}$ satisfying $\bar{e} \in E(\bar{e} ; \gamma)$. See Figure 3 .

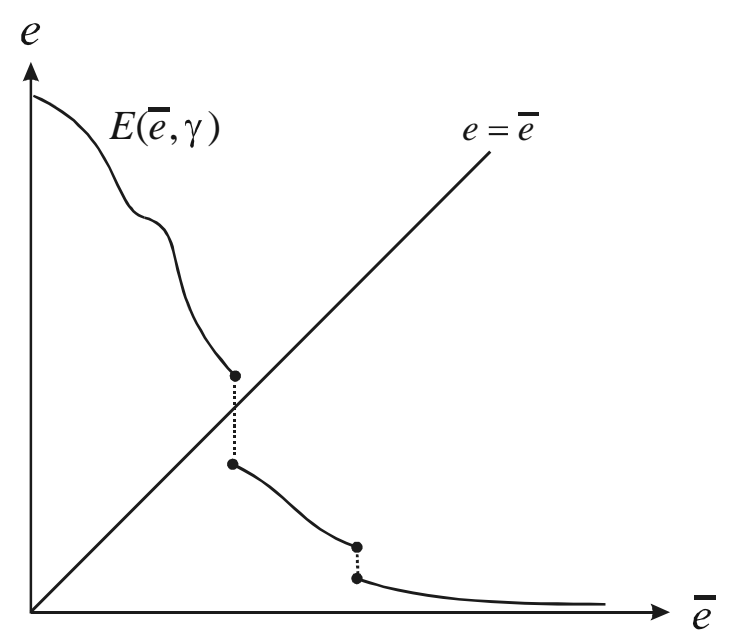

Figure 3: Equilibrium with bargaining.

To show the comparative static result on the equilibrium, consider $\gamma^{\prime}$ and $\gamma^{\prime \prime}$ such that $\gamma^{\prime \prime}>\gamma^{\prime}$. From part (c) of Lemma 2 we know that for all $e^{\prime} \in E\left(\bar{e} ; \gamma^{\prime}\right)$ and all $e^{\prime \prime} \in E\left(\bar{e} ; \gamma^{\prime \prime}\right)$, $e^{\prime} \geq e^{\prime \prime}$ with a strict inequality if $e^{\prime \prime}>0$. As a consequence, the fixed point $\bar{e}=E(\bar{e} ; \gamma)$ is strictly decreasing in $\gamma$. See Figure 4 .

Proof of Proposition 2. According to $(21), \varepsilon u^{\prime}(q)=c^{\prime}(q)$ in all trades iff $\gamma=\beta$. From (20), $e$ satisfies $\psi^{\prime}(e)=\alpha(1 / e) \mathcal{S}^{*}$. It is then easy to check that $e>\bar{e}^{*}$.

To show the second part of the Proposition, take two inflation rates $\gamma^{\prime \prime}$ and $\gamma^{\prime}$ with $\gamma^{\prime \prime}>\gamma^{\prime}>$ $\beta$. We first establish that real balances are decreasing with inflation. Let $\bar{e}^{\prime \prime} \in E\left(\bar{e}^{\prime \prime}, \gamma^{\prime \prime}\right)$ and $\bar{e}^{\prime} \in E\left(\bar{e}^{\prime}, \gamma^{\prime}\right)$. From Proposition 1 we know that $\bar{e}^{\prime \prime} \leq \bar{e}^{\prime}$, with strict inequality if $\bar{e}^{\prime \prime}>0$. From 


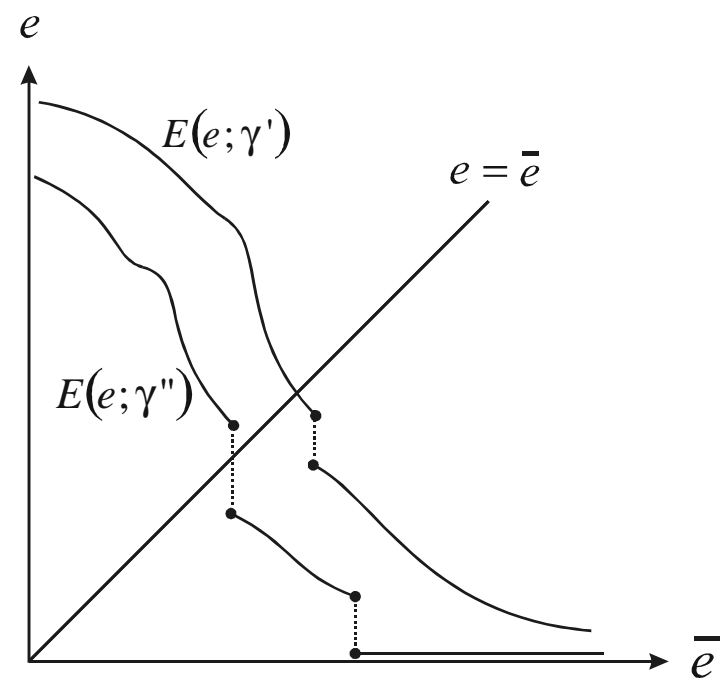

Figure 4: Inflation and equilibrium search intensity.

(20), $\bar{e}^{\prime}\left(\bar{e}^{\prime \prime}\right)$ implies a unique $z^{\prime}\left(z^{\prime \prime}\right)$, and $\bar{e}^{\prime \prime}<\bar{e}^{\prime}$ implies $z^{\prime \prime}<z^{\prime}$. Now consider the effect of inflation on output. Recall that $\hat{q}^{\prime}(z) \geq 0$; also from $(20), e^{\prime}(z)=\frac{\alpha \mathcal{S}^{\prime}}{\psi^{\prime \prime}-\alpha^{\prime} \mathcal{S}} \geq 0$. Differentiating (22) we find that

$$
\frac{\partial Y}{\partial z}=\frac{\zeta_{1}(e, 1) e^{\prime}(z) Y}{\zeta(e, 1)}+\zeta(e, 1) \hat{q}^{\prime}(z)[1-G(R)] \geq 0
$$

with strict inequality if $z<c\left(q_{1}^{*}\right)$. For the welfare effect of inflation use (20) to write $(1-\beta) V^{b}(z)=e \psi^{\prime}(e)-\psi(e)$ and get

$$
\frac{\partial V^{b}(z)}{\partial z}=\frac{e(z) e^{\prime}(z) \psi^{\prime \prime}[e(z)]}{1-\beta} \geq 0,
$$

with strict inequality if $z<c\left(q_{1}^{*}\right)$.

Proof of Lemma 3. We first show that the following problem,

$$
\max _{\mathrm{s} \in S, \hat{m}, e}\left[\alpha e \mathcal{S}_{b}\left(\hat{m}, F^{s}, \phi\right)-\psi(e)-\left(\frac{\gamma}{\beta}-1\right) \phi \hat{m}\right]
$$

with $\mathrm{S} \equiv[q(\hat{m}, \tilde{m}), d(\hat{m}, \tilde{m}), \theta]$ and subject to $\theta \geq 0, \hat{m} \geq 0, e \geq 0, d(\hat{m}, \tilde{m}) \leq \hat{m}$, and

$$
\max _{\hat{m} \geq 0}\left[\alpha_{s} \mathcal{S}_{s}\left(m_{b}, \hat{m}, \phi\right)-\left(\frac{\gamma}{\beta}-1\right) \phi \hat{m}\right] \geq U^{s}
$$


reduces to the one in the statement of the lemma. We proceed in several steps. Let $[q(\cdot, \cdot), d(\cdot, \cdot), \theta]$ be part of the solution to the buyer's problem. Then:

(i). If the submarket $\mathrm{s} \equiv[q(\cdot, \cdot), d(\cdot, \cdot), \theta]$ is active, then $d\left(m_{b}, m_{s}\right)>0$.

Assume not; then $\mathcal{S}_{s}\left(m_{b}, m_{s}, \phi\right)=-c\left[q\left(m_{b}, m_{s}\right)\right]$ and therefore the left-hand side of the seller's participation constraint (45) is strictly negative. But in any period sellers can achieve $0 \leq U^{s}$ meaning that $(45)$ is violated and hence the submarket $\mathrm{S} \equiv[q(\cdot, \cdot), d(\cdot, \cdot), \theta]$ is inactive.

(ii). If the submarket $\mathrm{S} \equiv[q(\cdot, \cdot), d(\cdot, \cdot), \theta]$ is active, then the contract $\left[q\left(m_{b}, m_{s}\right), d\left(m_{b}, m_{s}\right)\right]$ is independent of $m_{s}$ and sellers carry no cash into submarket $\mathrm{s}$.

Assume not; suppose that

$$
\phi d\left(m_{b}, m_{s}\right)-c\left[q\left(m_{b}, m_{s}\right)\right]>\phi d\left(m_{b}, 0\right)-c\left[q\left(m_{b}, 0\right)\right]
$$

and that the seller chooses to carry $m_{s}^{\prime}>0$ into submarket $\mathrm{s}$. (If the above inequality does not hold, then it immediately follows that a seller would choose $\left.m_{s}=0\right)$. Then a seller's payoff in submarket $\mathrm{S}$ is

$$
\alpha_{s}\left\{\phi d\left(m_{b}, m_{s}^{\prime}\right)-c\left[q\left(m_{b}, m_{s}^{\prime}\right)\right]\right\}-\left(\frac{\gamma}{\beta}-1\right) \phi m_{s}^{\prime} .
$$

Consider the contract $\left[\hat{q}\left(m_{b}\right), \hat{d}\left(m_{b}\right)\right]$ where terms of trade are independent of the seller's money holdings, i.e., $\hat{q}\left(m_{b}\right)=q\left(m_{b}, m_{s}^{\prime}\right)$ and $\hat{d}\left(m_{b}\right)=d\left(m_{b}, m_{s}^{\prime}\right)$. It yields the seller

$$
\begin{gathered}
\alpha_{s}\left\{\phi \hat{d}\left(m_{b}\right)-c\left[\hat{q}\left(m_{b}\right)\right]\right\}=\alpha_{s}\left\{\phi d\left(m_{b}, m_{s}^{\prime}\right)-c\left[q\left(m_{b}, m_{s}^{\prime}\right)\right]\right\} \\
>\alpha_{s}\left\{\phi d\left(m_{b}, m_{s}^{\prime}\right)-c\left[q\left(m_{b}, m_{s}^{\prime}\right)\right]\right\}-\left(\frac{\gamma}{\beta}-1\right) \phi m_{s}^{\prime}
\end{gathered}
$$

meaning that the seller's participation constraint is violated and hence the submarket is inactive.

Parts (i) and (ii) and the fact that $\gamma>\beta$ imply that any active submarket $\mathrm{s} \equiv[q(\cdot, \cdot), d(\cdot, \cdot), \theta]$ will have $q\left(m_{b}, m_{s}\right)=q\left(m_{b}\right)$ and $d\left(m_{b}, m_{s}\right)=m_{b}$. (The terms of trade are independent of the seller's money holdings, sellers carry no cash, and buyers hand over all their cash to sellers in every trade.) This establishes part (a) and allows us to rewrite the buyer's problem as

$$
\max _{q, m, \theta, e}\left[\alpha(\theta) e[u(q)-\phi m]-\psi(e)-\left(\frac{\gamma}{\beta}-1\right) \phi m\right],
$$

subject to $q \geq 0, m \geq 0, \theta \geq 0, e \geq 0$, and $\alpha_{s}(\theta)[\phi m-c(q)] \geq U^{s}$. Letting $z=\phi m$ we get the expressions in part (b) of the statement of the lemma.

(c). We first show that the maximizers $(q, z, e)$ lie in a compact set. Suppose the buyer chooses $\left(q^{\prime}, z^{\prime}\right)$ with $q^{\prime}>q^{*}$. Then the seller's surplus is $z^{\prime}-c\left(q^{\prime}\right)$ and the buyer's is $u\left(q^{\prime}\right)-z^{\prime}$. 
But note that the contract $\left(q^{*}, z^{*}\right)$ with $z^{*}=c\left(q^{*}\right)+z^{\prime}-c\left(q^{\prime}\right)$ keeps the seller's expected surplus unchanged but gives the buyer surplus $u\left(q^{*}\right)-z^{*}=u\left(q^{*}\right)-c\left(q^{*}\right)-z^{\prime}+c\left(q^{\prime}\right)>u\left(q^{\prime}\right)-z^{\prime}$. So we conclude that $q \in\left[0, q^{*}\right]$. Since $\psi^{\prime}(e) \rightarrow+\infty$ as $e \rightarrow 1$, we know that at the optimum, $e \in[0,1]$. Finally, we can restrict $z \in[c(q), u(q)]$ without affecting the value of the program, since choosing $u(q)-z<0$ yields value 0 (and this can be achieved by setting $e=z=0$ ), and choosing $z-c(q)<0$ implies the submarket is inactive. Thus, the value of the program is not affected by assuming $z \in[c(q), u(q)]$. We can invert $\alpha_{s}=\zeta(1 / \theta, 1)$ and use it to define $\theta\left(\alpha_{s}\right)$, so we can think of $\alpha_{s}$ as the choice variable. Then, our assumptions on the matching function imply that $\alpha_{s} \in[0,1]$. Now the problem in part (b) of the lemma can be restated as

$$
\max _{q, z, \alpha_{s}, e}\left[e \alpha\left[\theta\left(\alpha_{s}\right)\right][u(q)-z]-\psi(e)-\left(\frac{\gamma}{\beta}-1\right) z\right],
$$

subject to $\left(q, z, \alpha_{s}, e\right) \in \Gamma\left(U^{s}\right)$, where

$\Gamma\left(U^{s}\right)=\left\{\left(q, z, \alpha_{s}, e\right) \in \mathbb{R}^{4}: q \in\left[0, q^{*}\right], z \in[c(q), u(q)], \alpha_{s}, e \in[0,1]\right.$, and $\left.\alpha_{s}[z-c(q)] \geq U^{s}\right\}$.

Since the objective function is continuous and the constraint correspondence $\Gamma$ is continuous and compact valued, the correspondence $\Upsilon\left(U^{s}\right)$ is nonempty and upper-hemi continuous.

Proof of Proposition 3. (a). Suppose $\left(q\left(U^{s}\right), z\left(U^{s}\right), e\left(U^{s}\right), \theta\left(U^{s}\right)\right) \in \Upsilon\left(U^{s}\right)$, and let $r\left(U^{s}\right)=e\left(U^{s}\right) \theta\left(U^{s}\right)$. We denote $r_{H}\left(U^{s}\right)$ and $r_{L}\left(U^{s}\right)$ the greatest and the least element of the set $\left\{r \in \mathbb{R}: r=e\left(U^{s}\right) \theta\left(U^{s}\right)\right\}$. Then, we define the correspondence $\hat{E}\left(U^{s}\right)$ as follows:

$$
\hat{E}\left(U^{s}\right)=\left\{r \in \mathbb{R}: r=\sigma r_{H}\left(U^{s}\right)+(1-\sigma) r_{L}\left(U^{s}\right) \text { for some } \sigma \in[0,1]\right\}
$$

This is the set of all convex combinations of $r_{H}\left(U^{s}\right)$ and $r_{L}\left(U^{s}\right)$. With this notation, condition (C2) can be written as $1 \in \hat{E}\left(U^{s}\right)$. All we need to do to establish that an equilibrium exists is show that there exists a $U^{s}$ that satisfies this condition. (i) From the buyer's objective function we know that $U^{s}>u\left(q^{*}\right)-c\left(q^{*}\right)$ implies $\hat{E}\left(U^{s}\right)=\{0\}$. (ii) Now suppose $U^{s}=0$. We want to show that in this case we have $e\left(U^{s}\right)>0$ and $\theta\left(U^{s}\right)=+\infty$ for all elements in $\Upsilon\left(U^{s}\right)$. Suppose $\theta<\infty$; then the seller's participation constraint implies the buyer should set $z=c(q)$. If $\max _{q, z, e}\left\{e[u(q)-c(q)]-\psi(e)-\left(\frac{\gamma}{\beta}-1\right) c(q)\right\}>0$, then the buyer chooses $e>0$ and wants to set $\theta=+\infty$ to maximize his chances to trade. This means that $r\left(U^{s}\right)=e\left(U^{s}\right) \theta\left(U^{s}\right) \rightarrow+\infty$ as $U^{s} \rightarrow 0$ and therefore all elements in $\hat{E}\left(U^{s}\right)$ approach $+\infty$ as $U^{s} \rightarrow 0$. Given that $E\left(U^{s}\right)$ is 
upper hemi continuous, Parts (i) and (ii) imply that there exists a $U^{s}$ such that $1 \in \hat{E}\left(U^{s}\right)$. See Figure 5.

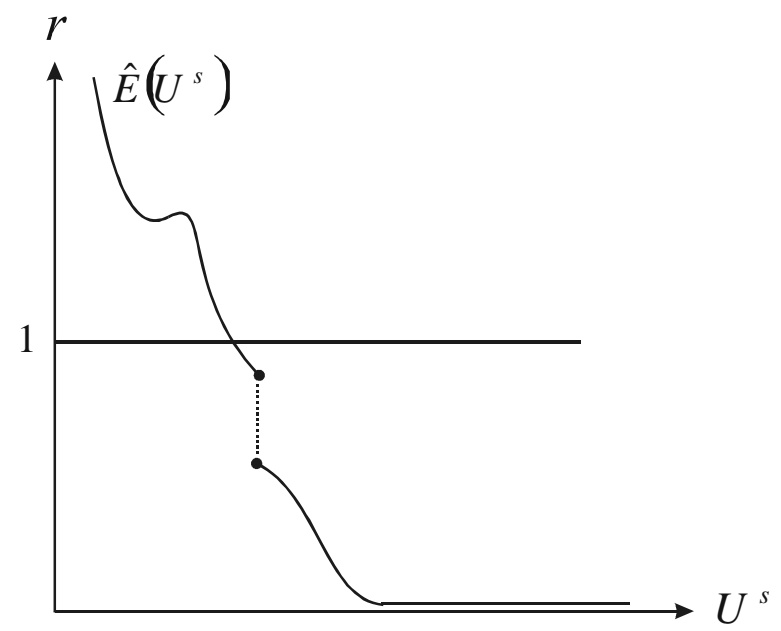

Figure 5: Existence of equilibrium under price posting.

Lemma 4 The buyer's problem in part (b) of Lemma 3 has a unique solution for $\gamma$ close to $\beta$.

Proof of Lemma 4. In what follows we assume that $U^{s}<u\left(q^{*}\right)-c\left(q^{*}\right)$, which has to hold in equilibrium. The seller's participation constraint can be rewritten as $z=c(q)+$ $U^{s} / \alpha_{s}(\theta)$. Substituting $z$ into the buyer's objective allows us to rewrite the buyer's problem as $\max _{(q, \theta, e) \in \mathbb{R}_{3+}} \Psi(q, \theta, e)$, where

$$
\Psi(q, \theta, e) \equiv e \alpha(\theta)\left[u(q)-c(q)-\frac{U^{s}}{\alpha_{s}(\theta)}\right]-\psi(e)-\left(\frac{\gamma}{\beta}-1\right)\left[c(q)+\frac{U^{s}}{\alpha_{s}(\theta)}\right] .
$$

If $\gamma=\beta$ the first-order conditions give:

$$
\begin{aligned}
q & =q^{*} \\
\psi^{\prime}(e) & =\alpha(\theta)\left[u\left(q^{*}\right)-c\left(q^{*}\right)-\frac{U^{s}}{\alpha_{s}(\theta)}\right] \\
U^{s} & =\alpha^{\prime}(\theta)\left[u\left(q^{*}\right)-c\left(q^{*}\right)\right] .
\end{aligned}
$$


From our assumptions, $\alpha^{\prime}$ is strictly decreasing, $\alpha^{\prime}(0)=1$ and $\alpha^{\prime}(\infty)=0 .{ }^{25}$ Given that $\frac{U^{s}}{u\left(q^{*}\right)-c\left(q^{*}\right)} \in[0,1]$, there is a unique $\theta$ that solves (48). Given this $\theta$, since $\psi^{\prime \prime}>0$, there is a unique $e$ that solves (47). Given that $U^{s}<u\left(q^{*}\right)-c\left(q^{*}\right)$, it can be checked that $\theta>0$ and $\max _{(q, \theta, e) \in \mathbb{R}_{3+}} \Psi(q, \theta, e)>0$. To show that $\Psi(q, \theta, e)$ is strictly concave in the neighborhood of the solution for $\gamma=\beta$, we compute:

$$
\begin{aligned}
& \Psi_{q q}=e \alpha(\theta)\left[u^{\prime \prime}(q)-c^{\prime \prime}(q)\right]-\left(\frac{\gamma}{\beta}-1\right) c^{\prime \prime}(q), \\
& \Psi_{e e}=-\psi^{\prime \prime}(e) \\
& \Psi_{\theta \theta}=e \alpha^{\prime \prime}(\theta)[u(q)-c(q)]+\left(\frac{\gamma}{\beta}-1\right)\left(\frac{\alpha_{s}^{\prime \prime}(\theta) \alpha_{s}(\theta)-2\left[\alpha_{s}^{\prime}(\theta)\right]^{2}}{\left[\alpha_{s}(\theta)\right]^{3}} U^{s}\right) \\
& \Psi_{q e}=\alpha(\theta)\left[u^{\prime}(q)-c^{\prime}(q)\right] \\
& \Psi_{q \theta}=e \alpha^{\prime}(\theta)\left[u^{\prime}(q)-c^{\prime}(q)\right] \\
& \Psi_{e \theta}=\alpha^{\prime}(\theta)[u(q)-c(q)]-U^{s} .
\end{aligned}
$$

At $\gamma=\beta$ and $q=q^{*}$, we have $\Psi_{q e}=\Psi_{q \theta}=\Psi_{e \theta}=0$ and $\Psi_{q q}<0, \Psi_{e e}<0$ and $\Psi_{\theta \theta}<0$. Since the Hessian is continuous, the function $\Psi(q, \theta, e)$ is strictly concave in the neighborhood of the solution under the Friedman Rule and hence for $\gamma$ in the neighborhood of $\beta$. Thus, $\Psi(q, \theta, e)$ admits a unique local maximum in the neighborhood of $q=q^{*}$. The first-order necessary condition with respect to $q$, is: $e \alpha(\theta)\left[u^{\prime}(q)-c^{\prime}(q)\right]=(\gamma / \beta-1) c^{\prime}(q)$. So any other candidate for an optimum must be such that either $\theta$ or $e$ is in the neighborhood of 0 which would imply that $\max _{q, \theta, e} \Psi(q, \theta, e)$ is close to 0 (and it can be made arbitrarily close to 0 by choosing $\gamma$ arbitrarily close to $\beta)$. Given that $\max _{(q, \theta, e) \in \mathbb{R}_{3+}} \Psi(q, \theta, e)>0$ at $\gamma=\beta$, such candidates can be eliminated.

Proof of Proposition 4. As argued above the statement of the proposition, the Friedman Rule implements the planner's solution, so welfare decreases as we move away from $\gamma=\beta$. For the second part combine (32)-(34) to get the following two equations in $e$ and $q$.

$$
\begin{aligned}
& \frac{u^{\prime}(q)}{c^{\prime}(q)}=1+\frac{\gamma-\beta}{\alpha e \beta} \\
& \psi^{\prime}(e)=\zeta_{1}(e, 1) \frac{u^{\prime}(q)}{\eta\left(\frac{1}{e}\right) u^{\prime}(q)+\left[1-\eta\left(\frac{1}{e}\right)\right] c^{\prime}(q)}[u(q)-c(q)],
\end{aligned}
$$

\footnotetext{
${ }^{25}$ The fact that $\alpha^{\prime}(0)=1$ comes from our assumption that $\lim _{\theta \rightarrow 0} \frac{\alpha(\theta)}{\theta}=1$. The fact that $\alpha^{\prime}(\infty)=0$ comes from our assumption that $\lim _{\theta \rightarrow \infty} \alpha(\theta)=1$.
} 
where $\zeta_{1}(e, 1)$ is the partial derivative of the matching function with respect to its first argument. By Lemma 4, for $\gamma$ close to $\beta$ (49) and (49) characterize the unique equilibrium. Condition (49) defines a monotonic relationship between $q$ and $e$ with slope $\frac{\partial e}{\partial q}=\frac{\beta\left(c^{\prime \prime} u^{\prime}-u^{\prime \prime} c^{\prime}\right) \zeta(e, 1)^{2}}{(\gamma-\beta) \zeta_{1}(e, 1)\left(c^{\prime}\right)^{2}}>0$. Similarly, if we think of (50) as a curve in $(q, e)$ space, its slope at $q^{*}$ has the same sign as

$$
\frac{\partial e}{\partial q}=\frac{\zeta_{1}\left(e^{*}, 1\right)\left[1-\eta\left(\frac{1}{e^{*}}\right)\right]\left[u^{\prime \prime}\left(q^{*}\right)-c^{\prime \prime}\left(q^{*}\right)\right]\left[u\left(q^{*}\right)-c\left(q^{*}\right)\right]}{u^{\prime}\left(q^{*}\right)\left\{\psi^{\prime \prime}\left(e^{*}\right)-\zeta_{11}\left(e^{*}, 1\right)\left[u\left(q^{*}\right)-c\left(q^{*}\right)\right]\right\}}<0 .
$$

Therefore, $e$ as a function of $q$ as defined by (50) is downward sloping at $q=q^{*}$. A small deviation from the Friedman Rule shifts the curve defined by (49) up in (q,e) space while (50) is not affected. This implies that $e$ increases and $q$ falls in response to the increase in $\gamma$. See Figure 2. 


\section{Appendix B : Competitive price posting by sellers}

In this appendix, we analyze the competitive search equilibrium assuming that sellers are those who post the price. We show that the equilibrium is equivalent to the one we have obtained assuming that buyers are those who set prices.

The price posting game is described as follows. At the beginning of each period, before buyers have made their choice of money holdings, each seller publicly announces a contract. A contract specifies the terms at which agents commit to trade as a function of the money holdings of the two agents. Buyers observe the different contracts and choose one to search for. They choose their real balances in the market for general goods and their search intensity in the search market.

Proposition 5 The sequence $\left\{\phi_{t}, Z_{t}\right\}$ with $Z_{t}=Z$ for all $t$ together with the collection

$$
\left\{U^{b}, U^{s},\left(q_{i}, z_{i}, e_{i}, \theta_{i}\right)_{i \in[0,1]}\right\}
$$

is a stationary competitive price posting monetary equilibrium by buyers if and only if it is a stationary competitive price posting monetary equilibrium by sellers.

Before proving this proposition, we must first reformulate the problems faced by buyers and sellers when the latter post prices and the former direct their search. The problem of a buyer holding $m$ dollars and searching for a seller in submarket $\mathrm{s}=(q, d, \theta)$ when the price of money in terms of general goods in the next centralized market is $\phi$ is summarized by:

$$
V^{b}(m, \mathrm{~s}, \phi)=\max _{e \geq 0}-\psi(e)+(1-\alpha e) W^{b}(m, \phi)+\alpha e\left\{u\left[q\left(m, m_{s}\right)\right]+W^{b}\left[m-d\left(m, m_{s}\right), \phi\right]\right\} .
$$

The lifetime expected utility of a buyer holding $m$ units of money at the beginning of the period, denoted $W^{b}(m, \phi)$, satisfies

$$
W^{b}(m, \phi)=\max _{x, y, \mathrm{~s} \in S, \hat{m} \geq 0}\left[x-y+\beta V^{b}\left(\hat{m}, \mathrm{~s}, \phi_{+1}\right)\right]
$$

subject to $\phi \hat{m}+x=\phi(m+T)+y$, where $S$ is the set of all submarkets that are active in the first subperiod and $T$ is the monetary transfer. Substituting the constraint into the objective,

$$
W^{b}(m, \phi)=\phi(m+T)+\max _{\mathrm{s} \in S, \hat{m} \geq 0}\left[\beta V^{b}\left(\hat{m}, \mathrm{~s}, \phi_{+1}\right)-\phi \hat{m}\right]
$$


This equation, which is identical to (30), states that buyers choose their money holdings and direct their search toward the submarket that maximizes their expected utility. Define

$$
\hat{W}^{b}(m, \mathrm{~s}, \phi)=\phi(m+T)+\max _{\hat{m} \geq 0}\left[\beta V^{b}\left(\hat{m}, \mathrm{~s}, \phi_{+1}\right)-\phi \hat{m}\right],
$$

so that $W^{b}(m, \phi)=\max _{\mathrm{s} \in S} \hat{W}^{b}(m, \mathrm{~s}, \phi)$.

The value of search to a seller holding $m$ units of money who has chosen to post terms of trade and tightness $(q, d, \theta)$ and hence to be in submarket $\mathrm{S}=(q, d, \theta)$ is given by

$$
V^{s}(m, \mathrm{~S}, \phi)=\left(1-\alpha_{s}\right) W^{s}(m, \phi)+\alpha_{s} \int\left\{-c[q(\tilde{m}, m)]+W^{s}[m+d(\tilde{m}, m), \phi]\right\} d F^{b}(\tilde{m}),
$$

where $F^{b}$ is the distribution of money holdings among buyers searching in submarket $\mathrm{s}$. The value of a seller entering the centralized market with $m$ dollars is

$$
\begin{gathered}
W^{s}(m, \phi)=\phi m+\max _{\mathrm{s}, \hat{m} \geq 0}\left[\beta V^{s}\left(\hat{m}, \mathrm{~s}, \phi_{+1}\right)-\phi \hat{m}\right] \\
\text { s.t. } \hat{W}^{b}\left(m^{b}, \mathrm{~s}, \phi\right) \geq W^{b}\left(m^{b}, \phi\right)
\end{gathered}
$$

This expression for $W^{s}$ is similar to (28), but differs in that the maximization is now subject to (52), the participation condition for buyers. The left-hand side of (52) is the expected utility of a buyer who chooses to search in submarket $\mathrm{s}$, and the right-hand side is the expected utility from searching in the submarket that maximizes his expected utility. Note that $\hat{W}^{b}\left(m^{b}, \mathrm{~s}, \phi\right)-$ $W^{b}\left(m^{b}, \phi\right)$ is independent of $m^{b}$ so that if (52) is satisfied for one value of $m_{b}$, it is satisfied for all values of $m_{b}$. The participation constraint (52) defines an implicit relationship between $\theta$ and the terms of trade $(q, d)$, and says that a submarket receives buyers only if it yields them the maximum level of utility they can achieve by searching another submarket. Submarkets for which (52) does not hold do not attract buyers and therefore shut down.

Here as in the body of the paper, we focus on stationary equilibria in which $M_{+1} / M=$ $\phi / \phi_{+1}=\gamma>\beta$. Since in this formulation the terms of trade $(q, d)$ are posted by sellers, we take a closer look at their maximization problem in the decentralized market. First note that since $W^{s}(m, \phi)=W^{s}(0, \phi)+\phi m$, the value function $V^{s}$ can be written as

$$
V^{s}(m, \mathrm{~s}, \phi)=\alpha_{s} \mathcal{S}_{s}\left(F^{b}, m, \phi\right)+\phi m+W^{s}(0, \phi)
$$

where $\mathcal{S}_{s}\left(F^{b}, m, \phi\right) \equiv \int\{\phi d(\tilde{m}, m)-c[q(\tilde{m}, m)]\} d F^{b}(\tilde{m})$. Substituting this into (51) gives

$$
W^{s}(m, \phi)=\phi m+\beta W^{s}\left(0, \phi_{+1}\right)+\beta \max _{\mathrm{s}, \hat{m}}\left\{\alpha_{s} \mathcal{S}_{s}\left(F^{b}, \hat{m}, \phi_{+1}\right)-\left(\frac{\gamma}{\beta}-1\right) \phi_{+1} \hat{m}\right\},
$$


with $\mathrm{S} \equiv[q(\tilde{m}, \hat{m}), d(\tilde{m}, \hat{m}), \theta]$, and subject to $(52), \theta \geq 0, \hat{m} \geq 0$ and $d(\tilde{m}, \hat{m}) \leq \tilde{m}$.

Lemma 5 Sellers carry no money.

Proof. Suppose that $m^{\prime}>0, q\left(\tilde{m}, m^{\prime}\right)$ and $d\left(\tilde{m}, m^{\prime}\right)$ are part of the solution to the seller's problem in (53). Clearly, since $\gamma>\beta$, posting $q(\tilde{m}, 0)$ and $d(\tilde{m}, 0)$ and setting $\hat{m}=0$ yields the seller strictly higher utility.

By virtue of Lemma 5, hereafter we write the terms of trade as $q\left(m_{b}\right)$ and $d\left(m_{b}\right)$, where $m_{b}$ denote the buyer's money holdings. Using Lemma 5 and the fact that $W^{b}(m, \phi)=W^{b}(0, \phi)+$ $\phi m$, the value function $V^{b}$ can be written as

$$
V^{b}(m, \mathrm{~s}, \phi)=\max _{e}\left\{\alpha e \mathcal{S}_{b}(m, \phi)-\psi(e)\right\}+\phi m+W^{b}(0, \phi)
$$

where $\mathcal{S}_{b}(m, \phi)=u[q(m)]-\phi d(m)$. Using this expression and the linearity of $W^{b}(m, \phi)$ in $m$, the participation constraint (52) can be expressed as

$$
\max _{e, m}\left\{\alpha e \mathcal{S}_{b}\left(m, \phi_{+1}\right)-\psi(e)-\left(\frac{\gamma}{\beta}-1\right) \phi_{+1} m\right\} \geq U^{b}
$$

where

$$
U^{b} \equiv \max _{q(m), d(m), \theta, e, m}\left\{\alpha e \mathcal{S}_{b}\left(m, \phi_{+1}\right)-\psi(e)-\left(\frac{\gamma}{\beta}-1\right) \phi_{+1} m\right\}
$$

subject to $e \geq 0, m \geq 0$. Therefore, a seller chooses which $\mathrm{S}=(q, d, \theta)$ to post by solving

$$
\max _{q(m), d(m), \theta}\left\{\alpha_{s} \int\{\phi d(\tilde{m})-c[q(\tilde{m})]\} d F^{b}(\tilde{m})\right\}
$$

subject to (54), $\theta \geq 0$ and $d(m) \leq m$ for all $m$. A seller posts (and commits to) terms of trade $[q(m), d(m)]$, namely how much output $q$ gets exchanged and how much money changes hands as a function of the money holdings of the buyer. Given these terms of trade, buyers choose money holdings, search intensity and a submarket to search in. It is convenient to think of the seller as posting a "menu" $[q(m), d(m)]$ that potentially depends on the money holdings of the buyer (money holdings are observable, just as in Section 2). When the buyer chooses money holdings he is choosing a particular "item" on the menu offered by the seller. If there are multiple solutions to the buyer's problem; i.e., several levels of cash holdings that maximize the left-hand side of (54), then buyers may show up with different money holdings, which is why in principle the seller has to take expectations using the cumulative density $F^{b}$. In fact, $m^{\prime} \in \operatorname{supp} F^{b}$ only if 
there is some $e^{\prime}$ such that $\left(e^{\prime}, m^{\prime}\right) \in \arg \max _{e, m}\left\{\alpha e \mathcal{S}_{b}\left(m, \phi_{+1}\right)-\psi(e)-\left(\frac{\gamma}{\beta}-1\right) \phi_{+1} m\right\}$. Also, if $[q(m), d(m)]$ solves the seller's problem, then $\phi d\left(m^{\prime}\right)-c\left[q\left(m^{\prime}\right)\right]=\phi d\left(m^{\prime \prime}\right)-c\left[q\left(m^{\prime \prime}\right)\right]$ for all $m^{\prime}, m^{\prime \prime} \in \operatorname{supp} F^{b} .{ }^{26}$ This means that the distribution of money holdings among buyers is payoff irrelevant for buyers and sellers. For this reason we will specialize the analysis to equilibria with a degenerate distribution of money holdings across buyers within each submarket. ${ }^{27}$ Lemma 6 shows that there is no loss of generality in restricting our attention to the set of contracts in which sellers require buyers to hand over all their cash. The basic idea is that since buyers would never pick an item off a menu that requires them to bring cash that will not be used in exchange, there is no loss in ignoring the class of menus that include such items.

Lemma 6 The seller's problem can be written as

$$
\max _{q(m), d(m), \theta}\left\{\alpha_{s}(\theta) \int\{\phi d(\tilde{m})-c[q(\tilde{m})]\} d F^{b}(\tilde{m})\right\}
$$

subject to (54), $\theta \geq 0$ and $d(m)=m$ for all $m$.

Proof. Suppose $\left(e^{\prime}, m^{\prime}\right) \in \arg \max _{e, m} \Lambda[e, m ; q(\cdot), d(\cdot), \theta]$, where

$$
\Lambda[e, m ; q(\cdot), d(\cdot), \theta] \equiv \alpha e\{u[q(m)]-\phi d(m)\}-\psi(e)-\left(\frac{\gamma}{\beta}-1\right) \phi m
$$

We want to show that if $[q(m), d(m)]$ solves the seller's problem, then it will never be the case that $d\left(m^{\prime}\right)<m^{\prime}$. We proceed by contradiction: suppose that the contract $[q(m), d(m)]$ solves the seller's problem and $d\left(m^{\prime}\right)<m^{\prime}$. Consider the contract $[\hat{q}(m), \hat{d}(m)]=[q(m), d(m)]$ for all $m \neq d\left(m^{\prime}\right)$, but with $\hat{d}(m)=m$ and $\hat{q}(m)=q\left(m^{\prime}\right)$ for $m=d\left(m^{\prime}\right)$. Then

$$
\begin{gathered}
\alpha e^{\prime}\left\{u\left[q\left(m^{\prime}\right)\right]-\phi d\left(m^{\prime}\right)\right\}-\psi\left(e^{\prime}\right)-\left(\frac{\gamma}{\beta}-1\right) \phi m^{\prime} \\
<\alpha e^{\prime}\left\{u\left[q\left(m^{\prime}\right)\right]-\phi d\left(m^{\prime}\right)\right\}-\psi\left(e^{\prime}\right)-\left(\frac{\gamma}{\beta}-1\right) \phi d\left(m^{\prime}\right) .
\end{gathered}
$$

\footnotetext{
${ }^{26}$ If this was not the case, say if $\phi d\left(m^{\prime}\right)-c\left[q\left(m^{\prime}\right)\right]>\phi d\left(m^{\prime \prime}\right)-c\left[q\left(m^{\prime \prime}\right)\right]$, then the seller could simply pick $\left[q\left(m^{\prime \prime}\right), d\left(m^{\prime \prime}\right)\right]$ in such a way that no buyer planning to search the submarket would choose $m^{\prime \prime}$.

${ }^{27}$ From a welfare standpoint, this is not restrictive because - as mentioned above and formalized in Lemma 7 below - for each equilibrium with a nondegenerate distribution of money holdings for buyers within a submarket there is one with identical payoffs to all agents but no dispersion in money holdings within each submarket. Moreover, we will still be allowing for dispersion in buyers' money holdings across submarkets.
} 
Thus $\max _{e, m} \Lambda[e, m ; q(\cdot), d(\cdot), \theta]<\Lambda\left[e^{\prime}, m^{\prime} ; \hat{q}(\cdot), \hat{d}(\cdot), \theta\right]$. This together with the fact that $\phi \hat{d}\left(m^{\prime}\right)-c\left[\hat{q}\left(m^{\prime}\right)\right]=\phi d\left(m^{\prime}\right)-c\left[q\left(m^{\prime}\right)\right]$ implies that $[q(m), d(m)]$ is not a solution to the seller's problem.

The following lemma shows that the seller's problem can be simplified even further and expected utilities of buyers and sellers remain unchanged if we specialize the analysis to the case in which a seller only chooses among "single-item menus."

Lemma 7 Let $z \equiv \phi m$. Given $U^{b}$, the seller's problem can be written as

$$
\max _{q, z, \theta} \alpha_{s}(\theta)[z-c(q)]
$$

subject to $q \geq 0, z \geq 0$, and $\alpha_{s}(\theta) \geq 0$ if

$$
\max _{e}\left\{\alpha(\theta) e[u(q)-z]-\psi(e)-\left(\frac{\gamma}{\beta}-1\right) z\right\} \geq U^{b}
$$

or $\alpha_{s}(\theta)=0$ otherwise.

Proof. First, we show that the maximization problem in Lemma 6 is equivalent to

$$
\max _{q(m), d(m), \theta}\left\{\alpha_{s} \int\{\phi d(\tilde{m})-c[q(\tilde{m})]\} d F^{b}(\tilde{m})\right\}
$$

subject to (54), $\theta \geq 0, d(m)=m$ for all $m$ and $q(m) \in \mathcal{C}^{\prime}$, where

$$
\begin{gathered}
\mathcal{C}^{\prime}=\left\{q(m): \mathbb{R}_{+} \rightarrow \mathbb{R}_{+} \text {s.th. } q(m)=q \geq 0 \text { if } m=m^{\prime}\right. \text { and } \\
\left.q(m)=0 \text { if } m \neq m^{\prime} \text { for some } m^{\prime} \in \mathbb{R}_{+}\right\}
\end{gathered}
$$

Let $\mathcal{C}$ denote the set of all functions from $\mathbb{R}_{+}$into $\mathbb{R}_{+}$. Then the difference is that the choice of $q(m)$ is unrestricted in Lemma 6 but is now required to lie in $\mathcal{C}^{\prime} \subset \mathcal{C}$. Suppose that $\left[q^{*}(m), m, \theta^{*}\right]$ and $\left(e^{\prime}, m^{\prime}\right)$ solve the unrestricted problem. That is, $\left[q^{*}(m), m, \theta^{*}\right]$ solves the seller's problem we posed in Lemma 6 and $\left(e^{\prime}, m^{\prime}\right) \in \arg \max _{e, m} \Lambda\left[e, m ; q^{*}(m), m, \theta^{*}\right]$. Then the seller's payoff is $\alpha_{s}\left(\theta^{*}\right)\left\{\phi m^{\prime}-c\left[q^{*}\left(m^{\prime}\right)\right]\right\}$ and the buyer's is $\Lambda\left[e^{\prime}, m^{\prime} ; q^{*}(m), m, \theta^{*}\right]$. But there is a contract $[\hat{q}(m), m]$ with $\hat{q}(m) \in \mathcal{C}^{\prime}$ that implements the same solution, namely $\hat{q}(m)=q^{*}(m)$ for $m=m^{\prime}$ and $\hat{q}(m)=0$ for $m \neq m^{\prime}$. Therefore since $\left[q^{*}(m), m, \theta^{*}\right]$ solves the seller's problem when $q(m)$ is unrestricted, and it yields the same payoffs as $\left[\hat{q}(m), m, \theta^{*}\right]$, 
it follows that $\left[\hat{q}(m), m, \theta^{*}\right]$ solves the problem subject to the additional constraint $q(m) \in \mathcal{C}^{\prime}$. All this means that the value of the seller's program is not altered if we restrict his maximization by requiring that $q(m) \in \mathcal{C}^{\prime}$. Hence we can write the value of the seller's program as

$$
\max _{q, m, \theta} \alpha_{s}(\theta)[\phi m-c(q)]
$$

with $\alpha_{s}(\theta) \geq 0$ if $\max _{e}\{\alpha(\theta) e[u(q)-\phi m]-\psi(e)-(\gamma / \beta-1) \phi m\} \geq U^{b}$, and $\alpha_{s}(\theta)=0$ otherwise. Letting $z \equiv \phi m$ we get the expressions in the statement.

According to Lemma 7 we can think of the seller's problem as one of choosing a simple contract $(q, z)$, specifying a level of real balances $z$ such that the buyer that enters the submarket with $z$ gets $q$ in exchange for $z$ and no surplus if he carries any other level of real balances. In principle, different sellers may choose to operate in different submarkets by offering different $(q, z)$ pairs. Buyers then choose what submarket to search in (given the "one-item" contracts offered by sellers this essentially amounts to choosing a level of real balances $z$ ) and with what intensity. Given $U^{b}$, the seller's problem can be written as the following:

Definition 3 Given a money supply process $M_{+1} / M=\gamma$, a stationary competitive price posting monetary equilibrium by sellers is a sequence $\left\{\phi_{t}, Z_{t}\right\}$ with $Z_{t}=Z$ for all $t$ and a collection $\left\{U^{b}, U^{s},\left(q_{i}, z_{i}, e_{i}, \theta_{i}\right)_{i \in[0,1]}\right\}$ such that:

(C1') Given $U^{b},\left(q_{i}, z_{i}, \theta_{i}, e_{i}\right)$ solve the problem posed in Lemma 7

(C2') $\int_{[0,1]} e_{i} \theta_{i} d i=1$

(C3') $\int_{[0,1]} z_{i} d i=Z$

$\left(C 4^{\prime}\right) \phi_{t}=\frac{Z}{M_{t}}$

$\left(C 5^{\prime}\right) U^{s}=\alpha_{s}\left(\theta_{i}\right)\left[z_{i}-c\left(q_{i}\right)\right]$

Proof of Proposition 5. Note that conditions (C2)-(C4) and (C2')-(C4') are identical. Thus all we need to show is that $\left\{U^{b}, U^{s},\left(q_{i}, z_{i}, e_{i}, \theta_{i}\right)_{i \in[0,1]}\right\}$ satisfy $(\mathrm{C} 1)$ and (C5) if and only if they satisfy ( $\mathrm{C}^{\prime}$ ) and (C5'). The seller's problem in Lemma 7 can be conveniently written as $\max _{q, z, \theta, e} \mathcal{L}^{s}$ where

$$
\mathcal{L}^{s}=\alpha_{s}[z-c(q)]+\rho^{b}\left\{\alpha e[u(q)-z]-\psi(e)-\left(\frac{\gamma}{\beta}-1\right) z-U^{b}\right\}
$$


and $\rho^{b}$ is the multiplier on the buyer's participation constraint. The first-order necessary conditions corresponding to $\left(\mathrm{C} 1^{\prime}\right)$ are

$$
\begin{aligned}
\rho^{b} \alpha e u^{\prime}(q) & =\alpha_{s} c^{\prime}(q) \\
\rho^{b}\left[\alpha e+\frac{\gamma}{\beta}-1\right] & =\alpha_{s} \\
\rho^{b} e \alpha^{\prime}(\theta)[u(q)-z] & =-\alpha_{s}^{\prime}(\theta)[z-c(q)] \\
\rho^{b}\left\{\alpha[u(q)-z]-\psi^{\prime}(e)\right\} & =0 \\
\rho^{b}\left\{\alpha e[u(q)-z]-\psi(e)-\left(\frac{\gamma}{\beta}-1\right) z-U^{b}\right\} & =0
\end{aligned}
$$

and $\left(\mathrm{C}^{\prime}\right)$ is

$$
U^{s}=\alpha_{s}(\theta)[z-c(q)]
$$

Similarly, the buyer's problem in Lemma 3 part (a) can be written as $\max _{q, z, \theta, e} \mathcal{L}^{b}$ where

$$
\mathcal{L}^{s}=\alpha e[u(q)-z]-\psi(e)-\left(\frac{\gamma}{\beta}-1\right) z+\rho^{s}\left\{\alpha_{s}[z-c(q)]-U^{s}\right\}
$$

and $\rho^{s}$ is the multiplier on the seller's participation constraint. The first-order necessary conditions corresponding to $(\mathrm{C} 1)$ are

$$
\begin{aligned}
\alpha e u^{\prime}(q) & =\rho^{s} \alpha_{s} c^{\prime}(q) \\
\alpha e+\frac{\gamma}{\beta}-1 & =\rho^{s} \alpha_{s} \\
e \alpha^{\prime}(\theta)[u(q)-z] & =-\rho^{s} \alpha_{s}^{\prime}(\theta)[z-c(q)] \\
\alpha[u(q)-z]-\psi^{\prime}(e) & =0 \\
\rho^{s}\left\{\alpha_{s}[z-c(q)]-U^{s}\right\} & =0
\end{aligned}
$$

and (C5) is

$$
U^{b}=\alpha e[u(q)-z]-\psi(e)-\left(\frac{\gamma}{\beta}-1\right) z .
$$

From (56) and (62) we see that $\rho^{b}=\frac{1}{\rho^{s}}$, and hence that (55) is identical to (61) and (57) is identical to (63). In addition, any active submarket has $\rho^{i}>0$ for $i=b, s$ and therefore (58)-(60) are identical to (64)-(66). 


\section{References}

[1] Ahmed, Shaghil and John H. Rogers (2000). "Inflation and the Great Ratios: Long Term Evidence From the U.S.," Journal of Monetary Economics, 45, 3-35.

[2] Berentsen, Aleksander, Guillaume Rocheteau and Shouyong Shi (2001). "Friedman Meets Hosios: Efficiency in Search Models of Money," mimeo.

[3] Bullard, James (1999). "Testing Long-Run Monetary Neutrality Propositions: Lessons From the Recent Research," Federal Reserve Bank of St. Louis Review, 57-78.

[4] Bullard, James and John Keating (1995). "The Long-Run Relationship Between Inflation and Output in Postwar Economies," Journal of Monetary Economics, 36, 477-496.

[5] Hosios, Arthur J. (1990). "On the Efficiency of Matching and Related Models of Search and Unemployment," Review of Economic Studies, 57, 279-298.

[6] King, Robert and Mark Watson (1997). "Testing Long-Run Neutrality," Federal Reserve Bank of Richmond Economic Quarterly, 83, 69-101.

[7] Kiyotaki, Nobuhiro and Randall Wright (1989). "On Money as a Medium of Exchange," Journal of Political Economy, 97, 927-954.

[8] Kiyotaki, Nobuhiro and Randall Wright (1991). "A Contribution to the Pure Theory of Money," Journal of Economic Theory, 53, 215-235.

[9] Kiyotaki, Nobuhiro and Randall Wright (1993). "A Search-Theoretic Approach to Monetary Economics," American Economic Review, 83, 63-77.

[10] Kocherlakota, Narayana (1998). "Money is Memory," Journal of Economic Theory, 81, $232-251$.

[11] Lagos, Ricardo and Randall Wright (2002). "A Unified Framework for Monetary Theory and Policy Analysis," mimeo.

[12] Lagos, Ricardo and Randall Wright (2003). "Dynamics, Cycles, and Sunspot Equilibria in 'Genuinely Dynamic, Fundamentally Disaggregative' Models of Money,' Journal of Economic Theory, 109, 156-171. 
[13] Lucas, Robert (2000). "Inflation and Welfare," Econometrica, 68, 247-274.

[14] Lucas, Robert and Edward C. Prescott (1974). "Equilibrium Search and Unemployment," Journal of Economic Theory, 7, 188-209.

[15] Moen, Espen R. (1997). "Competitive Search Equilibrium," Journal of Political Economy, 105, 385-411.

[16] Peterson, Brian and Shouyong Shi (2003). "Search, Price Dispersion and Welfare," mimeo.

[17] Rapach, David (2003). "International Evidence on the Long-Run Impact of Inflation," Journal of Money, Credit, and Banking, 35, 23-48.

[18] Rocheteau, Guillaume and Randall Wright (2002). "Money in Search Equilibrium, in Competitive Equilibrium, and in Competitive Search Equilibrium," mimeo.

[19] Shi, Shouyong (1995). "Money and Prices: A Model of Search and Bargaining," Journal of Economic Theory, 67, 467-496.

[20] Shi, Shouyong (1997). "A Divisible Search Model of Fiat Money," Econometrica, 65, $75-102$.

[21] Shimer, Robert (1996). "Contracts in Frictional Labor Market," mimeo.

[22] Stokey, Nancy L. and Robert E. Lucas, Jr., with Edward C. Prescott (1989). Cambridge, Mass. and London: Harvard University Press, pp. xviii, 588.

[23] Topkis, Donald M. (1998). "Supermodularity and Complementarity," Princeton University Press, Princeton.

[24] Trejos, Alberto and Randall Wright (1995). "Search, Bargaining, Money, and Prices," Journal of Political Economy, 103, 118-141. 